PNL-5968

UC-95

\title{
Tribological Sinks in Emerging Industries: Electronics and Robotics
}

\author{
J. A. Russell \\ G. J. Hane
}

August 1986

Prepared for the U.S. Department of Energy under Contract DE-AC06-76RLO 1830

Pacific Northwest Laboratory Operated for the U.S. Department of Energy by Battelle Memorial Institute 


\title{
DISCLAIMER
}

This report was prepared as an account of work sponsored by an agency of the United States Government. Neither the United States Government nor any agency thereof, nor any of their employees, makes any warranty, express or implied, or assumes any legal liability or responsibility for the accuracy, completeness, or usefulness of any information, apparatus, product, or process disclosed, or represents that its use would not infringe privately owned rights. Reference herein to any specific commercial product, process, or service by trade name, trademark, manufacturer, or otherwise, does not necessarily constitute or imply its endorsement, recommendation, or favoring by the United States Government or any agency thereof. The views and opinions of authors expressed herein do not necessarily state or reflect those of the United States Government or any agency thereof.

\author{
PACIFIC NORTHWEST LABORATORY \\ operated by \\ BATTELLE \\ for the \\ UNITED STATES DEPARTMENT OF ENERGY \\ under Contract DE-AC06-76RLO 1830
}

\begin{tabular}{|c|c|}
\hline \multirow{2}{*}{\multicolumn{2}{|c|}{ Printed in the United States of America }} \\
\hline & \\
\hline \multicolumn{2}{|c|}{$\begin{array}{l}\text { Available from } \\
\text { National Technical Information Service }\end{array}$} \\
\hline \multicolumn{2}{|c|}{ United States Department of Commerce } \\
\hline \multicolumn{2}{|c|}{5285 Port Royal Road } \\
\hline \multicolumn{2}{|c|}{ Springfield, Virginia 22161} \\
\hline \multirow{2}{*}{\multicolumn{2}{|c|}{$\begin{array}{l}\text { NIIS Price Codes } \\
\text { Microfiche } A 01\end{array}$}} \\
\hline & \\
\hline \multicolumn{2}{|c|}{ Printed Copy } \\
\hline & Price \\
\hline Pages & Codes \\
\hline $001-025$ & $\mathrm{~A} 02$ \\
\hline 026-050 & $\wedge 03$ \\
\hline 051-075 & A04 \\
\hline $076-100$ & A05 \\
\hline $101-125$ & $A 06$ \\
\hline $126-150$ & A07 \\
\hline $151-175$ & $\mathrm{~A} 0 \mathrm{~B}$ \\
\hline $176-200$ & $\mathrm{~A} 09$ \\
\hline $201-225$ & A010 \\
\hline $226-250$ & A011 \\
\hline $251-275$ & A012 \\
\hline $276-300$ & A013 \\
\hline
\end{tabular}


TRIBOLOGICAL SINKS IN EMERGING

INDUSTRIES: ELECTRONICS AND

ROBOTICS

J. A. Russell

G. J. Hane

August 1986

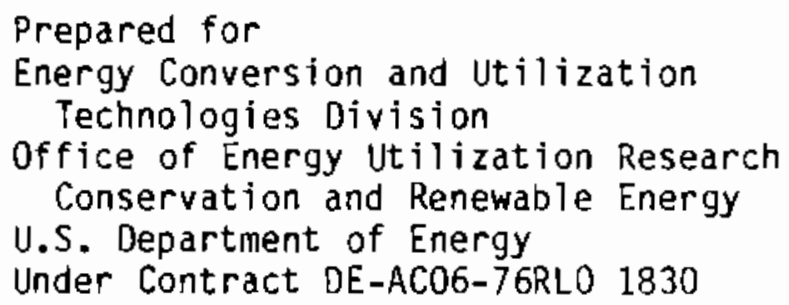

Pacific Northwest Laboratory

Richland, Washington 99352 
SUMMARY

This report describes a preliminary review of the impact of tribological effects--losses due to friction and wear--in two emerging industries: robotics and electronics. The study was conducted by Pacific Northwest Laboratory (PNL) for the Tribology Program of the Energy Conversion and Utilization Technologies (ECUT) Program in the U.S. Department of Energy (DOE).

Major sources of tribological wear in the robotics industry include the chains used to drive the robots and the joints in the elbow and wrist. In the electronics industry, the largest source of tribological wear is the particulate wear of vacuum pumps used in corrosive environments. Other significant sources of wear are the conveyor belts, blowers, and fans used for clean rooms, and the slicing, lapping and polishing operations for silicon wafers. A summary of the tribological wear mechanisms for both industries is given in Table S.1. The major loss mechanisms are friction and abrasion (abrasion includes 2-body wear, 3-body wear, gouging, grinding, erosion, and cutting wear).

Direct energy loss due to friction is a relatively small fraction of the energy consumed by the robotics and electronics industries. For the robotics

TABLE S.1. Wear Mechanisms in Emerging Industries

\begin{tabular}{|c|c|c|c|c|}
\hline Dperation & Friction & Abrasion & Adhesion & Tribochemical \\
\hline \multicolumn{5}{|l|}{ Electronics } \\
\hline slicing, dicing silicon & $x$ & $x$ & & \\
\hline Lapping, polishing & $x$ & $x$ & & \\
\hline Vacuum pumps & $x$ & $x$ & & $x$ \\
\hline Orilling, deburring & $x$ & $x$ & & \\
\hline Blowers and fans & $x$ & & & \\
\hline Conveyors & $x$ & $x$ & & \\
\hline Contact wear & $x$ & & $x$ & $x$ \\
\hline \multicolumn{5}{|l|}{ Robotics } \\
\hline Chain drives & $x$ & $x$ & & \\
\hline Elbow and wrist joints & $x$ & $x$ & & \\
\hline
\end{tabular}




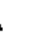

.

.

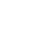


industry, the direct energy loss is estimated to be at most $5 \%$ of total energy consumption, and for the electronics industry, the direct energy loss is estimated to be about $0.1 \%$ of total industry energy consumption. The electronics industry has a lower percentage of direct energy loss due to tribological effects because many of the processing steps either do not have tribological components, or have very limited tribological wear. The direct energy losses are summarized in Table S.2.

Indirect energy loss due to tribological wear is also a relatively small fraction of the energy consumed by the robotics and electronics industries. For the robotics industry, the indirect losses are estimated to be about $1.5 \%$ of the total energy consumption, resulting from the embodied energy in the hydraulic fluid, chains, and bearings. For the electronics industry, the indirect losses are estimated to be about $0.2 \%$ of the total industry energy consumption, resulting almost entirely from the embodied energy in replacement vacuum pumps. The silicon slicing blades and the gold coatings, although their per unit embodied energy is relatively high, do not represent a high level of indirect energy consumption because the total weight of the tribologically-worn materials is low. The indirect energy losses are summarized in Table S.3.

TABLE S.2. Direct Tribological Energy Losses in Emerging Industries

\begin{tabular}{|c|c|c|}
\hline \multirow[b]{2}{*}{ Industry } & \multicolumn{2}{|c|}{$\begin{array}{c}\text { Direct Tribological Loss, } \\
\text { Btu/yr }\end{array}$} \\
\hline & 1983 & 2000 \\
\hline Robotics & $9.0 \times 10^{10}$ & $1.5 \times 10^{12}$ \\
\hline Electronics & $5 \times 10^{10}$ & \\
\hline
\end{tabular}

TABLE S.3. Indirect Tribological Energy Losses in Emerging Industries

\begin{tabular}{|c|c|c|}
\hline \multirow[b]{2}{*}{ Industry } & \multicolumn{2}{|c|}{$\begin{array}{c}\text { Direct Tribological Loss, } \\
\text { Btu/yr }\end{array}$} \\
\hline & 1983 & 2000 \\
\hline Robo & $2.8 \times 10^{10}$ & $1.1 \times 10^{11}$ \\
\hline Electronics & $9.0 \times 10^{10}$ & \\
\hline
\end{tabular}


Table S.4 provides an indication of the relative size of the tribological energy losses in robotics and electronics by comparing them to energy consumption of the industries as a whole, and to the total U.S. industrial energy consumption.

Although tribological energy losses for robot operation and electronics manufacturing are relatively small, the monetary and productivity losses are very significant. In the robotics industry, the cost of the electricity lost from tribological causes was estimated to be $\$ 0.6$ million in 1983 , rising to $\$ 8$ million by the year 2000. However, the cost of replacement of worn hydraulic $0 i 1$, chains, and bearings was estimated to be nearly $\$ 4$ million in 1983, rising to $\$ 44$ million by 2000 . Total monetary losses in the robotics industry due to tribological energy loss and parts replacement were estimated to be $\$ 4.4$ million in 1983 , rising to $\$ 51$ million by 2000 . The cost of replacing entire robots due to tribological wear also could potentially be significant.

In the electronics industry, the cost of the energy lost due to tribology is about 2 million dollars per year. However, the cost of vacuum pump replacement is about 67 million dollars, of worn gold coatings replacement is about 10 million dollars, and of worn slicing blades replacement is about 5 million dollars. The total monetary value of tribological losses in the electronics industry is at least 84 million dollars. The size of these losses has been enough to spur industrial research in improving vacuum pump durability and in developing coatings with a smaller percentage of gold.

Productivity losses due to friction and wear are also of great concern to the manufacturers and users of both robots and electronic equipment. The robotics manufacturers would like to increase reliability by reducing

TABLE S.4. Relative Size of Tribological Energy Losses

$\frac{\text { Sector }}{\text { U.S. industries }}$
Electronics industry
Robotics industry

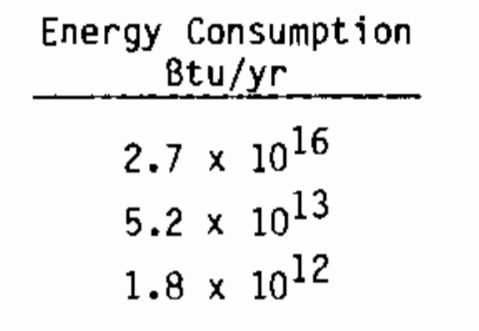


maintenance requirements and unexpected failures, to reduce the weight of bearing and lubrication systems to increase the system response speed, and increase the wear resistance of bearings to improve precision. The electronics manufacturers would like to reduce the exposure of pumps to particulates, so that pumps would last longer, reduce the wear between sliding gold coatings, so that circuit lifetime and reliability could be improved, and reduce the materials losses in silicon wafer production by developing long-wearing, ultra-thin slicers.

Another general area of improvement that was frequently mentioned is the need for a self-lubricating or dry lubricant or surface coating. Liquid lubri. cants have several disadvantages in both the electronics and the robotics industries. For robotics, the liquid lubricants are difficult to properly disperse when the robot arm is traveling through its series of motions. The liquid lubricants also require seals, which are susceptible to leakage and can cause a series of problems such as burning out motors, contaminating clean environments, or being washed away by solvent-filled external environments. For electronics, liquid lubricants can contaminate clean rooms because of dispersion and leakage. If human workers could be replaced by ultra-clean robots, the percentage of defective circuits could drop even as the circuits become smaller.

There is a need in both the robotics and electronics industries for tribological research that focuses on productivity losses due to tribology, on the development of solid lubricants for machinery, and on the protection of expensive materials. 
CONTENTS

SUMMARY

1.0 INTRODUCTION $\ldots \ldots \ldots \ldots \ldots \ldots \ldots \ldots \ldots \ldots \ldots \ldots \ldots \ldots \ldots \ldots \ldots \ldots \ldots$

2.0 TRIBOLOGICAL SINKS IN THE ROBOTICS INDUSTRY $\ldots \ldots \ldots \ldots \ldots \ldots \ldots \ldots \ldots . . \ldots$

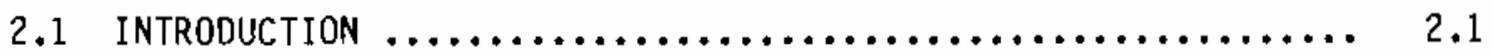

2.2 DEFINITION OF THE ROBOTICS INDUSTRY $\ldots \ldots \ldots \ldots \ldots \ldots \ldots \ldots \ldots .2$

2.3 TOTAL ENERGY USE IN THE ROBOTICS INDUSTRY ............. 2.2

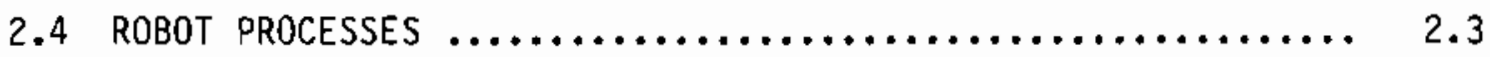

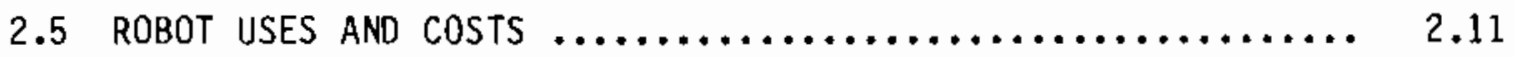

2.6 TRENDS IN THE ROBOTICS INDUSTRY $\ldots \ldots \ldots \ldots \ldots \ldots \ldots \ldots \ldots \ldots \ldots . \ldots \ldots$

2.7 TRIBOLOGICAL LOSSES IN THE ROBOTICS INDUSTRY ........... 2.13

2.7.1 Direct Energy Losses in the Robotics Industry ...... 2.14

2.7 .2 Indirect Energy Loss $\ldots \ldots \ldots \ldots \ldots \ldots \ldots \ldots \ldots \ldots \ldots . .14$

2.7.3 Productivity and Monetary Losses ............. 2.16

2.8 SUMMARY OF TRIBOLOGICAL SINKS IN THE ROBOTICS INDUSTRY $\ldots . . \quad 2.20$

3.0 TRIBOLOGICAL ENERGY LOSS IN THE ELECTRONICS INDUSTRY ......... 3.1

3.1 THE ELECTRONICS INDUSTRY $\ldots \ldots \ldots \ldots \ldots \ldots \ldots \ldots \ldots \ldots \ldots \ldots \ldots \ldots \ldots \ldots$

3.2 TOTAL ENERGY USE IN THE ELECTRONICS INDUSTRY ........... 3.1

3.3 PROCESSES IN THE ELECTRONICS INDUSTRY $\ldots \ldots \ldots \ldots \ldots \ldots \ldots \ldots \ldots$

3.3.1 Monocrystalline Silicon Production .............. 3.3

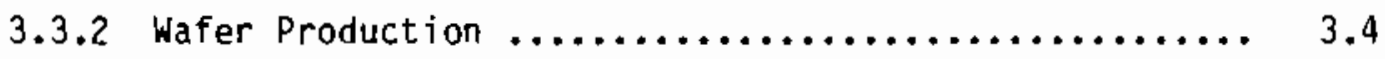

3.3.3 Integrated Circuit Production $\ldots \ldots \ldots \ldots \ldots \ldots \ldots \ldots . . \ldots$

3.3.4 Circuit Board Assembly .................... 3.9

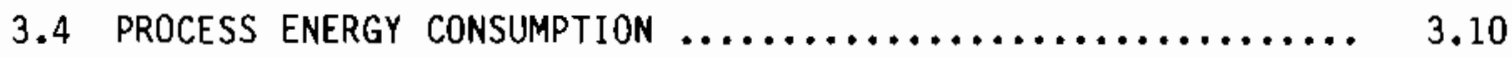

3.5 TRIBDLOGICAL LOSSES IN THE ELECTRONICS INDUSTRY $\ldots \ldots \ldots \ldots \ldots .3 .12$ 
3.5.1 Tribological Energy Losses $\ldots \ldots \ldots \ldots \ldots \ldots \ldots \ldots \ldots . . .13$

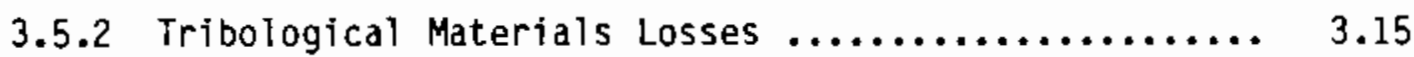

3.5.3 Tribological Monetary Losses .................. 3.19

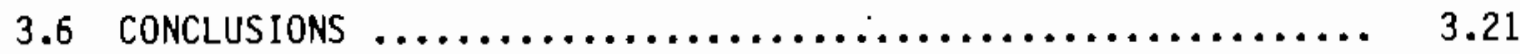

REFERENCES AND BIBLIOGRAPHY $\ldots \ldots \ldots \ldots \ldots \ldots \ldots \ldots \ldots \ldots \ldots \ldots \ldots \ldots, \ldots \ldots$, R.1 


\section{FIGURES}

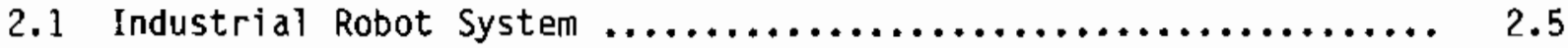

2.2 Reach Envelope of Industrial Robot $\ldots \ldots \ldots \ldots \ldots \ldots \ldots \ldots \ldots \ldots \ldots$

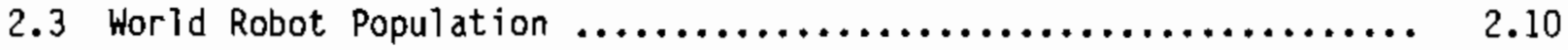




\section{TABLES}

S.1 Wear Mechanisms in Emerging Industries ................. ii

S.2 Direct Tribological Energy Losses in Emerging Industries ....... iv

S.3 Indirect Tribological Energy Losses in Emerging Industries ..... iv

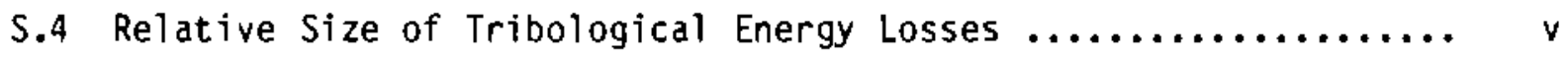

2.1 Robot Energy Use Estimates, $1983 \ldots \ldots \ldots \ldots \ldots \ldots \ldots \ldots \ldots \ldots \ldots \ldots$

2.2 Robot Energy Use Estimates for 1990 and $2000 \ldots \ldots \ldots \ldots \ldots \ldots \ldots$

2.3 Potential Applications of Various Types of Robots in Major

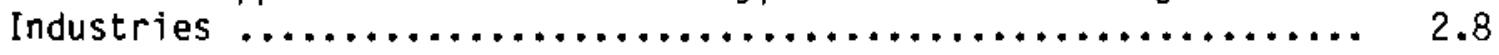

2.4 Total Population of Robots by Application $\ldots \ldots \ldots \ldots \ldots \ldots \ldots$

2.5 U.S. Robot Demand Trends by Application $\ldots \ldots \ldots \ldots \ldots \ldots \ldots \ldots . \ldots . \ldots 2 . \ldots 10$

2.6 Estimated Sales of U.S.-Based Robot Vendors $\ldots \ldots \ldots \ldots \ldots \ldots \ldots \ldots$...........

2.7 Price Range for Robots $\ldots \ldots \ldots \ldots \ldots \ldots \ldots \ldots \ldots \ldots \ldots \ldots \ldots \ldots \ldots \ldots \ldots . \ldots \ldots$

2.8 Direct Energy Losses and Costs in the Robotics Industry ....... 2.14

2.9 Indirect Energy Losses Due to Tribology in the Dperation
of Robots $\ldots \ldots \ldots \ldots \ldots \ldots \ldots \ldots \ldots \ldots \ldots \ldots \ldots \ldots \ldots \ldots \ldots \ldots \ldots \ldots \ldots \ldots$

2.10 Tribological Monetary Losses in the Robotics Industry ........ 2.17

3.1 Energy Consumption in Electronics $\ldots \ldots \ldots \ldots \ldots \ldots \ldots \ldots \ldots \ldots . \ldots \ldots$

3.2 Energy Consumption by Fuel Type in the Electronics Industry .... 3.2

3.3 Energy Consumption by Fuel Type for Semiconductor

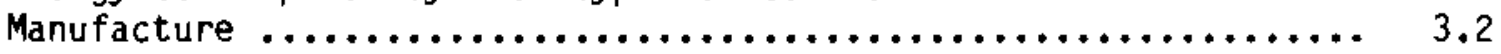

3.4 Energy Consumption by Fuel Type for "Other Electronics"

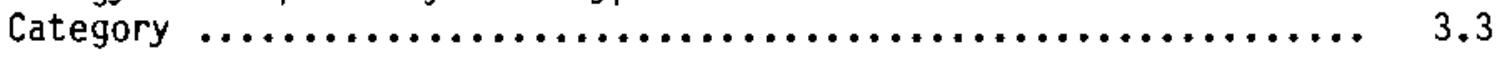

3.5 Energy Consumption for Silicon Wafer Production $\ldots \ldots \ldots \ldots \ldots \ldots . . . .12$

3.6 Energy for Silicon Wafers Versus Energy for Electronics ....... 3.12

3.7 Tribological Loss Mechanisms in the Electronics Industry ...... 3.14 
3.8 Direct Tribological Energy Loss in Electronics Industry ........ 3.16

3.9 Indirect Tribological Energy Losses in the Electronics

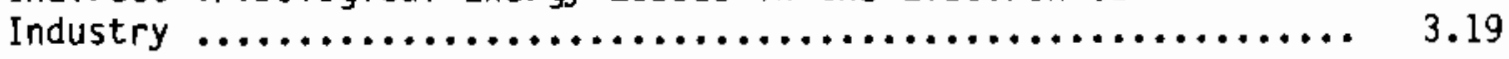

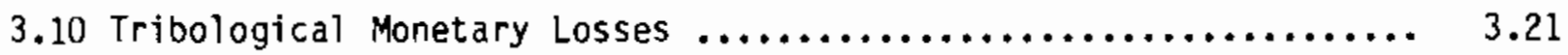




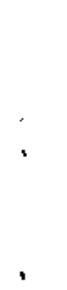




\subsection{INTRODUCTION}

Tribology is the science of friction and wear of materials that move in contact with other materials. This report describes a preliminary review of the impact of tribological effects in two emerging U.S. industries: robotics and electronics. The research involved identifying processes affected by tribology in these industries, and characterizing the nature and magnitude of the associated energy and material wear losses. Lost productivity caused by material wear was also evaluated, since it is of greater concern to the industries. These initial results could be used to plan research for improving the understanding of tribological processes and to develop better materials and lubricants to more effectively use energy and materials.

This study was conducted by Pacific Northwest Laboratory (PNL) for the Tribology Program of the Energy Conversion and Utilization Technologies (ECUT) Program in the U.S. Department of Energy (DOE). The goals of the ECUT Tribology Program are to develop wear models and to find better lubricants and more wear-resistant materials to reduce energy and material losses and to improve industrial productivity. A detailed review of tribological losses in emerging industries was needed for several reasons: to locate the most significant tribological sinks, to identify the quantity of energy and materials losses attributable to these sinks, and to estimate the effect these losses have on the emerging robotics and electronics industries. This report describes the development of this initial research.

The robotics industry was selected for this evaluation because tribological efficiency is important for robots' effective operation and because the use of robots in manufacturing processes is expected to increase significantly in the next century. The electronics industry was selected because it comprises a rapidiy developing segment of the economy, and is expected to be incorporated into most products and manufacturing processes in the future.

This report is divided into three sections. Sections 2.0 and 3.0 describe tribological sinks and energy losses in the robotics and electronics industries, respectively. Energy consumption figures for the robotics industry refer to operational requirements. Manufacturing energy requirements for 
metalforming have been discussed in an earlier report (Imhoff et al. 1985). Energy consumption figures for the electronics industry refer to manufacturing requirements, since electronics have no significant tribological energy losses during operation. Recommendations for further research are also provided. 


\subsection{TRIBOLOGICAL SINKS IN THE ROBOTICS INDUSTRY}

This chapter describes the current state of the robotics industry, the mechanics of robot operation, and the expected growth and trends in this industry. Estimates are made for productivity losses as well as for direct and indirect energy losses due to tribological sinks.

\subsection{INTRODUCTION}

The notion of using mechanical devices to relieve human workers of dangerous, burdensome, or tedious work existed long before the first robot design was patented in the 1950s. However, it was not until the late 1970s that robots began to be used extensively in industrial production in the United States. Since then the use of robots has expanded quickly and industrial robots have become an increasingly common sight in factories around the country.

The growth of industrial robots has been propelled by both their increasing flexibility and decreasing costs. Advances in sensors and computer controls have vastly expanded variety of applications for robots. These advances are responsible for the increasing use of robots in tasks ranging from aiding the physically handicapped, to performing simple surgery, to shearing sheep. The largest areas of immediate application, however, are in factory automation.

By the end of 1983, an estimated 9,400 robots were used in manufacturing processes in the United States and 67,360 worldwide (RIA 1985). Their uses in industrial plants range from handling parts to product assembly and inspection. In most applications robots have only begun to make an impact. Significant growth is anticipated to continue in the United States and throughout the world.

Although the sensors and computer controls for robots are becoming increasingly complex, the mechanical hardware of most robots is largely based on traditional technology. Most robots are composed of a series of bars connected by joints that allow the rotation and translation of the manipulator. The relative motion of the segments of the manipulator enables the robot to perform its tasks. However, the translation of force and motion from bar to 
bar creates inefficiencies due to friction and wear. It is at these joints that tribological advances can have a direct impact.

\subsection{DEFINITION OF THE ROBOTICS INDUSTRY}

The term "robot" is derived from Slavic languages and means "labor." Robots exist in such a variety of forms that a precise, universalty agreed upon definition is not available. Webster's Third New International Dictionary (1976) defines a robot as "a machine in the form of a human being that performs the functions of a human being but lacks emotions and sensitivity". Alternatively, the Robotic International Division of the Society of Manufacturing Engineers defines a robot as "a programmable multi-functional manipulator designed to move material, parts, tools, or specialized devices through variable programmed motions for the performance of a variety of tasks" (Koren 1985).

The concept of a robot that would perform repetitions manufacturing tasks can be traced to patents submitted by G. C. Devol in 1954 (Nof 1985). In thest? patents he described a controlled mechanical arm that would be capable of performing industrial tasks. The first industrial robot was installed by Unimation in 1961. During the early development of robots much of the pioneering work in their computer control was performed at Stanford University and the Massachusetts Institute of Technology (MIT). By the 1970s, however, the lead in the application of robotic systems had shifted to Japan. Since the late 1970s a tremendous growth has occurred in the use of robots in the U.S., Japan, and in several European nations. In the U.S., for example, between 1979 and 1983 there was a six-fold increase in the annual sales of robots, from 443 to 2,666 per year.

\subsection{TOTAL ENERGY USE IN THE ROBOTICS INDUSTRY}

In 1983, the energy required for operating robots consumed approximately $1.8 \times 10^{12} \mathrm{Btu} /$ year. (a) Electricity is the only type of energy consumed in

(a) All estimates of electricity use assume a Btu equivalent at $33 \%$ conversion efficiency. 
operating robots. Table 2.1 lists the energy use estimates for different types of robots, with the assumption that the robots operate an average of two shifts per day, or 5840 hours per year.

The amount of electricity currently consumed by the robotics industry is about $2 \times 10^{12}$ Btu/year. However, the total energy consumption is expected to rise as the number of robots increases. Table 2.2 lists the number of robots of each type that are expected to be in use in 1990 and 2000 , and the estimated electric energy requirements. Data used for these projections are discussed in Section 2.5. The table shows that by the year 2000 , approximately $30 \times 10^{12}$ Btu/year of electricity will be required for robot operation.

\subsection{ROBOT PROCESSES}

Modern robotic systems usually have three parts: the manipulator, the drives, and the controller. A typical robotic system is shown in Figure 2.1. The manipulator is the body of the robot, or its mechanical moving structure.

TABLE 2.1. Robot Energy Use Estimates, $1983^{(a)}$

\begin{tabular}{|c|c|c|c|c|}
\hline Category & Quantity & Power Use & $\mathrm{Btu} / \mathrm{yr}$ & $\%$ of total \\
\hline Spot welding & 2269 & $4 \mathrm{kWe}$ & $5.5 \times 10^{11}$ & 31 \\
\hline Arc welding & 1002 & $2 \mathrm{kHe}$ & $1.2 \times 10^{11}$ & 7 \\
\hline Painting/coating & 265 & $10 \mathrm{kWe}$ & $1.6 \times 10^{11}$ & 9 \\
\hline Finishing & 203 & $2 \mathrm{kWe}$ & $2.5 \times 10^{10}$ & 1 \\
\hline As sembly & 1525 & $1 \mathrm{kWe}$ & $9.2 \times 10^{10}$ & 5 \\
\hline Loading/unloading & 783 & $1 \mathrm{kWe}$ & $4.7 \times 10^{10}$ & 3 \\
\hline Material/hand 1 ing & 2466 & $5 \mathrm{kWe}$ & $7.4 \times 10^{11}$ & 41 \\
\hline Other & 887 & $1 \mathrm{kWe}$ & $5.4 \times 10^{10}$ & 3 \\
\hline Total & 9400 & & $1.8 \times 10^{12}$ & $\overline{100}$ \\
\hline
\end{tabular}

(a) The figures for the number of units and power level were developed from estimates given in several references (Baranson 1983, ITA 1984, Koren 1985, RIA 1985, Smith 1983, Zeldman 1984) and from interviews with manufacturers. The figures for energy use were developed by assuming that the robots operate two shifts per day. 
TABLE 2.2. Robot Energy Use Estimates for 1990 and $2000^{(a)}$

\begin{tabular}{|c|c|c|c|c|c|c|}
\hline \multirow[b]{2}{*}{ Category } & \multicolumn{3}{|c|}{1990} & \multicolumn{3}{|c|}{2000} \\
\hline & Quantity & Percent & $\begin{array}{l}\text { Energy Use } \\
\text { (日tu/year) }\end{array}$ & Quantity & Percent & $\begin{array}{l}\text { Energy Use } \\
\text { (Btu/year) }\end{array}$ \\
\hline Spot welding & 2,500 & 17 & $6.04 \times 10^{11}$ & 3,000 & 1.5 & $7.24 \times 10^{11}$ \\
\hline Are welding & 1,800 & 12 & $2.17 \times 10^{11}$ & 4,000 & 2 & $4.83 \times 10^{11}$ \\
\hline $\begin{array}{l}\text { Materials Hand- } \\
\text { ling and Cast- } \\
\text { ing (ineluding } \\
\text { load ing and } \\
\text { unloading }\end{array}$ & 3,900 & 26 & $7.07 \times 10^{11}$ & 40,000 & 20 & $7.24 \times 10^{12}$ \\
\hline $\begin{array}{l}\text { Painting/coating/ } \\
\text { FInlshing }\end{array}$ & 750 & 5 & $4.53 \times 10^{11}$ & 2,000 & 1 & $1.21 \times 10^{13}$ \\
\hline Assembly & 4,500 & 30 & $2.72 \times 10^{11}$ & 130,000 & 65 & $7.86 \times 10^{12}$ \\
\hline other & 1,500 & 10 & $9.05 \times 10^{10}$ & 22,000 & 11.5 & $1.33 \times 10^{12}$ \\
\hline Total & $\overline{15,000}$ & $\overline{100}$ & $2.34 \times 10^{12}$ & $2 \longdiv { 2 0 0 , 0 0 0 }$ & 100 & $2.9 \times 10^{13}$ \\
\hline
\end{tabular}

(a) The projections for the number of units were developed from estimates glven in several references (Baranson 1983, ITA 1984, RIA 1985, Smlth and WIIson 1983, Zeldman 1984) and from intervlews wth manufacturers. The flqures for energy use rere developed by assuming that the robots operate two shitts per day.

The drives activate the joints of the manipulator. A computer acts as the mind of the robot, serving as the controller and storer of task programs.

Within the limits of this general structure, robots take a large number of forms. Robots are frequently categorized by three characteristics: 1) the mode of operation, 2) the complexity of control, and 3) the manipulator geometry. The two principal modes of operation are point-to-point and continuous path. In point-to-point operations the arm travels in a straight line between designated points to perform its task. Examples would be spot welding and loading and unloading tasks. In continuous path operations, the robot performs a task along a designated path, such as automobile painting and arc welding.

Robots are also categorized by the complexity of their control. Nonservocontrolled robots are characterized by limited control strategies with limited flexibility, as in the design of pick-and-place operations. The drives are typically hydraulic or pneumatic with feedhack to the control system provided 


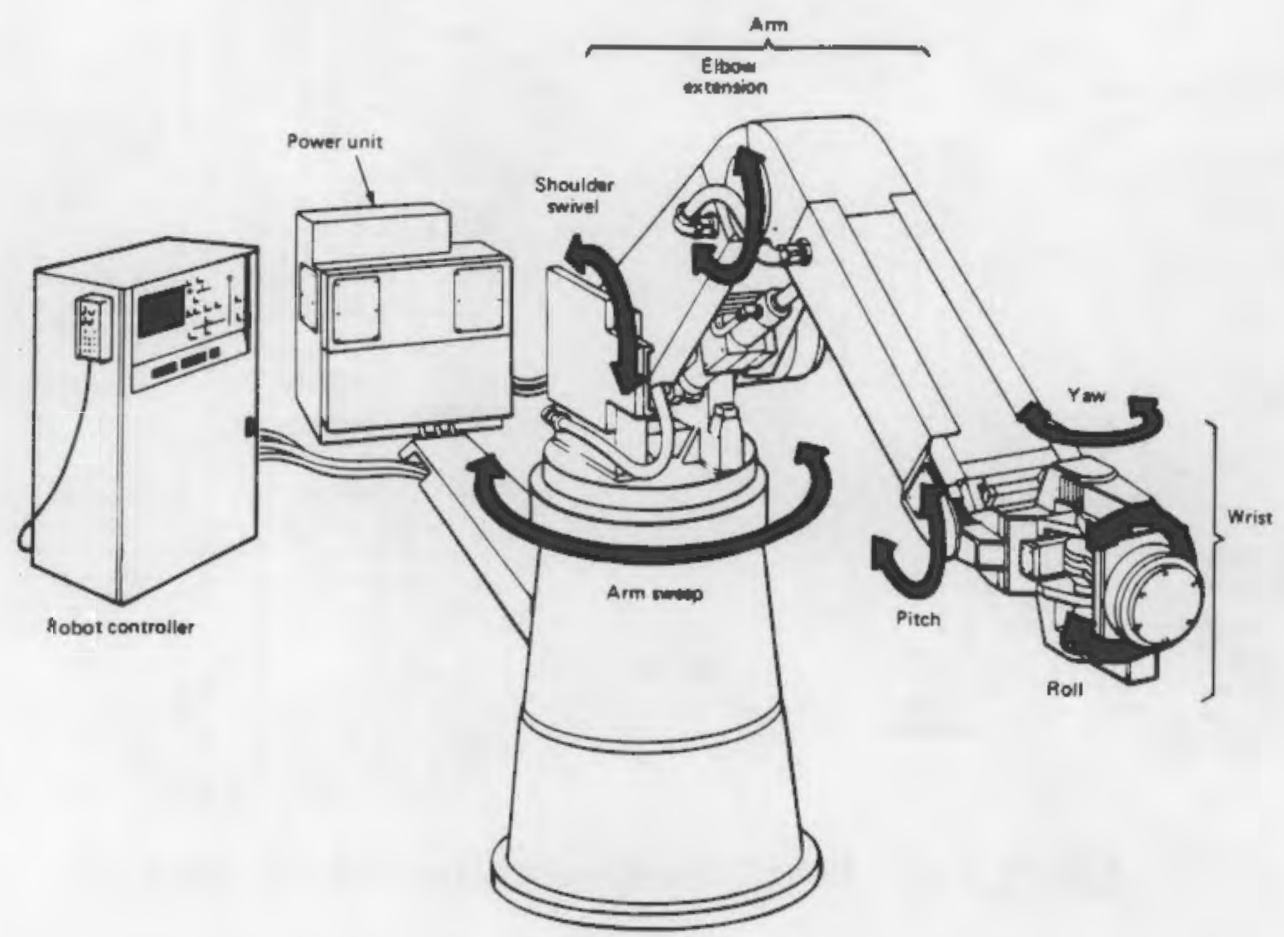

FIGURE 2.1. Industrial Robot System

by 1 imit switches or stoppers. In contrast, servo-controlled robots are directed in closed loop strategies and are usually driven with the aid of a servomotor.

The third means of categorization often used is the type of manipulator geometry. The manipulator geometry determines the flexibility and the reach envelope of the robot. Such an envelope is illustrated in Figure 2.2. The four geometrics involved are 1) cartesian, 2) cylindrical, 3) spherical, and 4) articulated. These designs progressively trade greater flexibility for decreased precision. Cartesian manipulators are limited to providing motion along one of three perpendicular axes, which limits the flexibility of this design. The limited motion does, however, provide a robot with movement that can be very precisely controlled. The second type of manipulator geometric is the cylindrical coordinate, which can direct operations within a cylindrical envelope with a vertical axis. This design is slightly more flexible but less precise than the Cartesian arrangement and is often used in loading and unloading operations. Next, the spherical coordinate robot provides another increase 

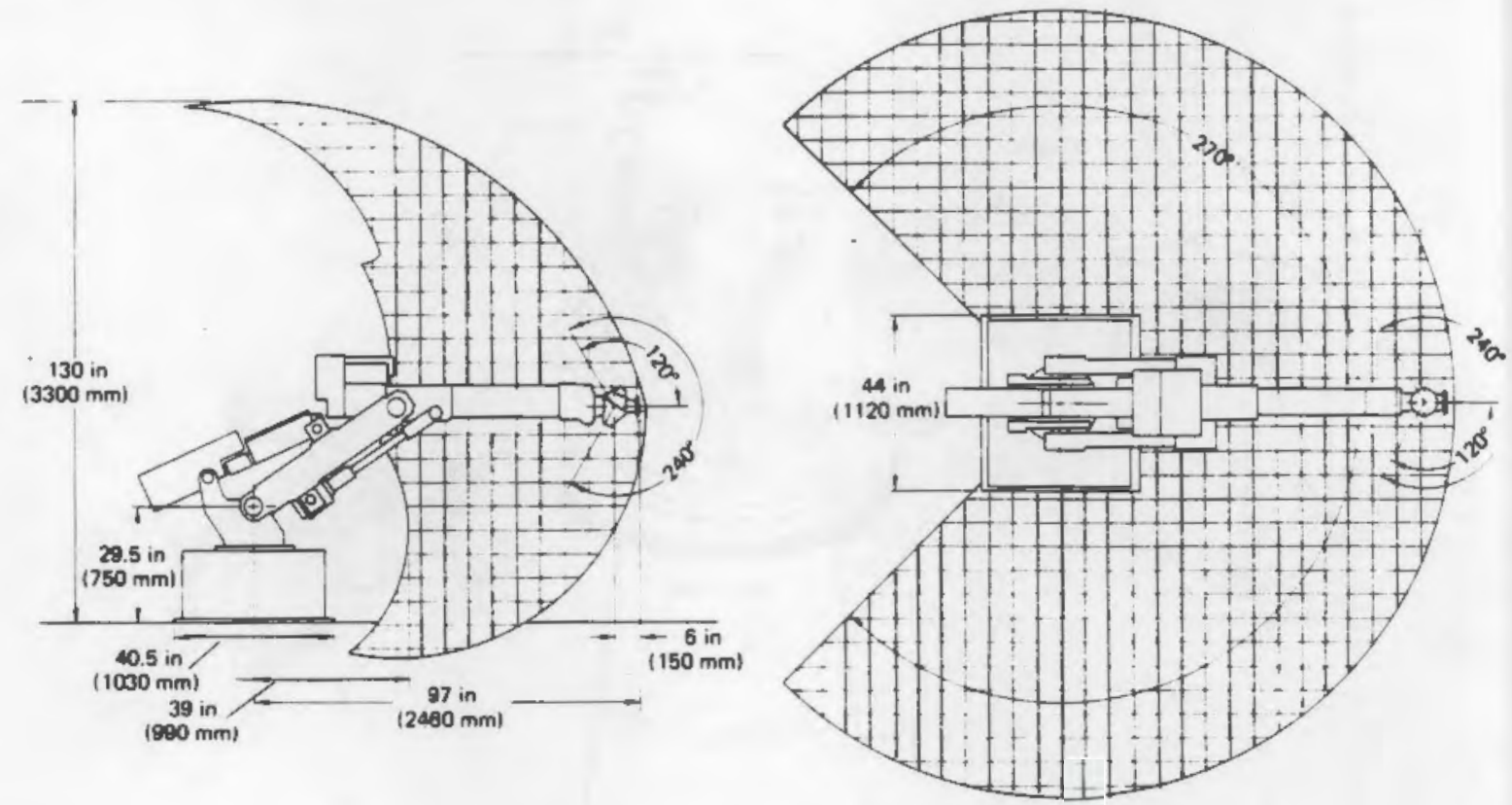

FIGURE 2.2. Reach Envelope of Industrial Robot

in flexibility by extending the working envelope to a hemisphere. Finally, the articulated manipulator provides the greatest flexibility in operation and most closely resembles the human arm. Although the multiple joints provide flexible motion, they also reduce precision. This spatial imprecision caused by each joint of the articulated manipulator is compounded at the working end of the arm.

\subsection{ROBOT USES AND COSTS}

Common tasks that are performed by industrial robots include

- Spot Welding

- Arc Welding

- Materials Handling

- Surface Treatment

- Assembly.

Each of these tasks imposes different requirements on robot designs. For example, in spot welding, the welding gun is relatively heavy $(10-80 \mathrm{~kg})$, and dc-motor-driven robots typically cannot handle the load. Therefore most spot 
welding robots are powered hydraulically. In contrast, in arc welding the welding gun is not usually very heavy. These robots are usually powered with dc servomotors. Spray painting robots require a great deal of flexibility in the motion of the robot. Most automobile painter robots are designed with six degrees of freedom.

The current major remaining uses of robots are in the home appliance, aerospace, electronics, and off-road equipment industries (ITA 1986). In addition to these industrial uses, the Census Bureau estimates that about $25 \%$ of the robots are used for educational, hobby, or recreational purposes. The potential use of robots, however, extends well beyond these industries. Table 2.3 illustrates the potential applicability of the various categories of robots to major manufacturing industries.

The distribution of robots performing these tasks in 1983 is summarized in Table 2.4. This table shows that spot welding and materials handiing were the predominant uses in 1983, together accounting for $61 \%$ of the tasks performed by robots. Assembly robots accounted for $16 \%$ of the U.S. robot population. Shown for comparison are the robot populations in Japan, West Germany and France. There are significantly more applications in Japan, which has more than half of the total population of robots in use in the world. This is graphically illustrated in Figure 2.3.

The automobile industry has pioneered many of the uses of industrial robots in manufacturing processes. Spot welding robots are being used widely in this industry, and robot pointers are becoming increasingly common. The Institute of Science and Technology at the University of Michigan estimated that in 1984 the automobile industry accounted for $51 \%$ of all robot sales (Industrial Heating 1985) and 35\% of the installed base (ITA 1986).

Table 2.5 shows a projection for the change in the distribution in the use of robots by 1990 . Materials handling will maintain a similar relative proportion, while a significant reduction will occur in the proportion of spot welders and a substantial growth in the use of robots for assembly. The reason for the proportionate shrinkage of spot welders is that the market for spot welding robots is expected to reach saturation by the middle of the 1980s. Beyond that point, spot welding robots are expected to be principally a 
TABLE 2.3. Potential Applications of Various Types of Robots in Major Industries

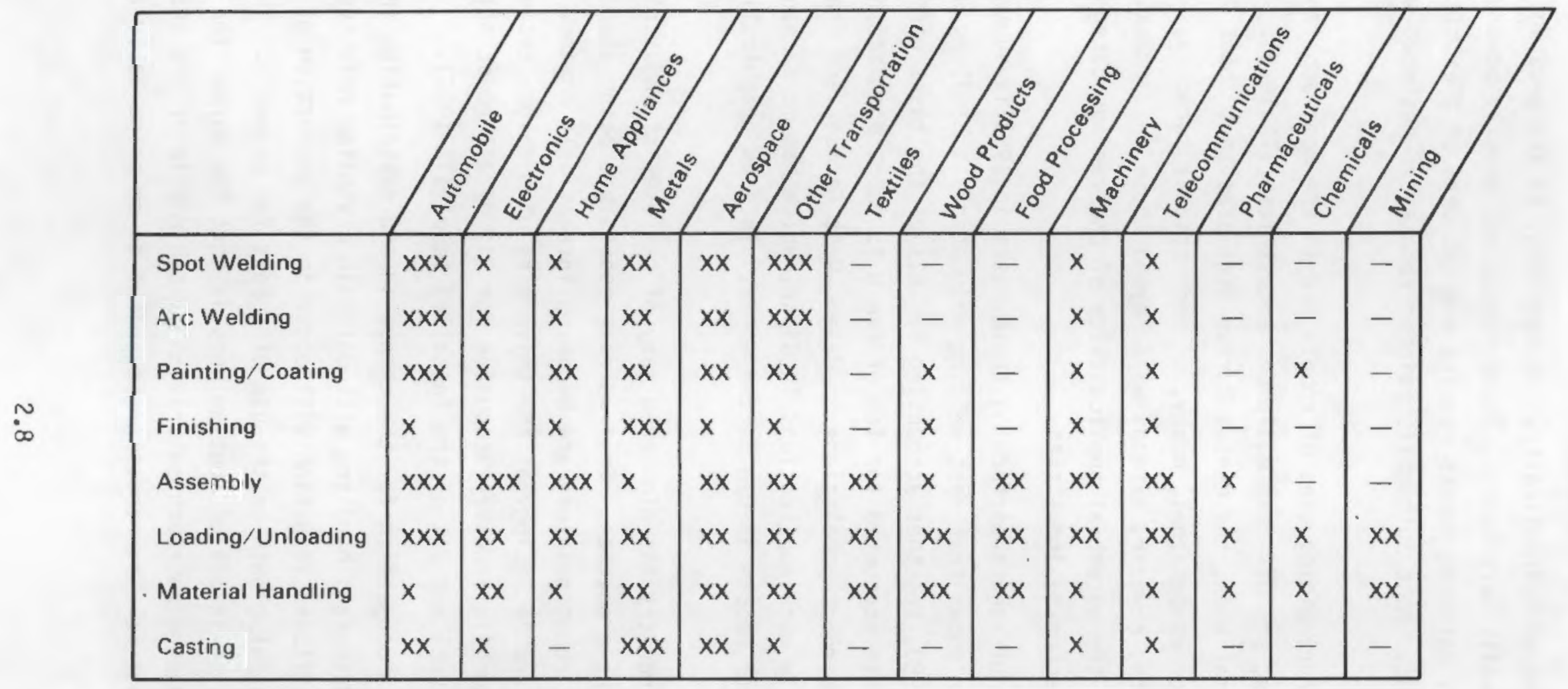

$X X X$ High level of use or potential use

XX Moderate level of use or potential use

$x \quad$ Low level of use or potential use 
TABLE 2.4. Total Population of Robots by Application (RIA 1985)

(End of 1983)

\begin{tabular}{|c|c|c|c|c|c|c|c|c|c|c|}
\hline & $\begin{array}{c}\begin{array}{c}\text { Spot } \\
\text { Welding }\end{array} \\
\end{array}$ & $\begin{array}{c}\text { Arc } \\
\text { Welding } \\
\end{array}$ & $\begin{array}{l}\text { Painting/ } \\
\text { Coating } \\
\end{array}$ & Finishing & Assembly & $\begin{array}{c}\text { Loading } \\
\text { Unloading } \\
\end{array}$ & $\begin{array}{l}\text { Material } \\
\text { Handling } \\
\end{array}$ & Casting & Other & Total \\
\hline Japan & 5,806 & 6,036 & 1456 & -- & 10,737 & 3,690 & 10,217 & 1,039 & 2,284 & 41,265 \\
\hline United States & 2,269 & 1,002 & 265 & 203 & 1,525 & 783 & \multicolumn{2}{|c|}{$--2,466--$} & 887 & 9,400 \\
\hline (percentage) & 24 & 11 & 3 & 2 & 16 & 8 & & 26 & 9 & \\
\hline West Germany & 1,560 & 856 & 586 & 22 & 248 & 320 & 194 & 132 & 882 & 4,800 \\
\hline France & 560 & 251 & 147 & 45 & 140 & & $-694-$ & & 173 & 2,010 \\
\hline
\end{tabular}




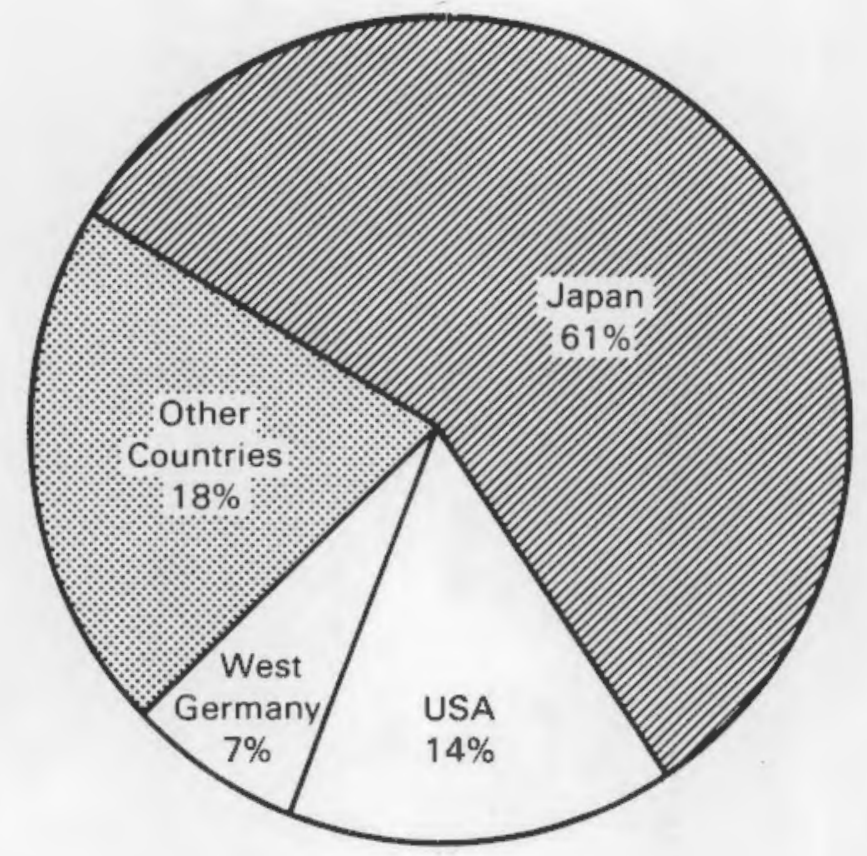

FIGURE 2.3. World Robot Population, 1983 (RIA 1985) (by percentage)

TABLE 2.5. U.S. Robot Demand Trends by Application (Baranson 1983)

\begin{tabular}{|c|c|c|}
\hline Application & $\begin{array}{c}\text { Percent } \\
1983 \\
\end{array}$ & $\begin{array}{c}\text { Percent } \\
1990 \\
\end{array}$ \\
\hline Spot Welding & 24 & $15-20$ \\
\hline Arc Welding & 11 & $10-20$ \\
\hline $\begin{array}{l}\text { Materials Handling } \\
\text { (including machine } \\
\text { loading and } \\
\text { unloading) }\end{array}$ & 34 & $25-35$ \\
\hline Surface Treatment & 5 & 5 \\
\hline Assembly & 16 & $25-40$ \\
\hline Other & 9 & $7-14$ \\
\hline
\end{tabular}

replacement market. The growth in assembly applications is expected to arise from improvements in sensors and controls, such as vision and tactile sensing capabilities, that will allow improved positioning accuracy. 
During the early 1980 s, sales of industrial robots experienced an annual growth of 600-700 units per year, as shown in Table 2.6. Although growth in sales during 1982 and 1983 fell to 23-26\%, growth surged again in 1984, with sales increasing by almost $40 \%$ over the previous year. In the first quarter of 1985 U.S. robot suppliers reported a record $243 \%$ increase in new orders (ASTM Standardization News 1985).

In 1983, the average cost of an industrial robot was estimated to be $\$ 50,000-\$ 70,000$ (Baranson 1983 and ITA 1984). The prices for robots in typica? applications range from $\$ 10,000-\$ 150,000$. A survey of robot prices in other countries that are making significant investments in robots showed a similar range of prices, as shown in Table 2.7 .

The average installed cost of an industrial robot in the U.S. in 1983 was estimated to be $\$ 100,000-\$ 120,000$. For multi-robot systems the installed cost was estimated at two to four times the cost of the robot, and for robots used for assembly, the installed cost has been estimated at three to four times the cost of the robot (Baranson 1983).

\subsection{TRENDS IN THE ROBOTICS INDUSTRY}

Robots are expected to play an increasing role in production processes in U.S. industry because of several advantages that robots have compared with human labor. These advantages include increased flexibility, reliability, and overall productivity. Robots also can be programmed to perform a variety of tasks and can be used in environments that are often hostile to human health

TABLE 2.6. Estimated Sales of U.S.-Based Robot Vendors

\begin{tabular}{|c|c|c|c|c|c|}
\hline & & & Year & & \\
\hline & 1981 & 1982 & 1983 & 1984 & 1985 \\
\hline $\begin{array}{l}\text { Total Value } \\
\text { (\$ million) }\end{array}$ & 155 & 190 & 240 & 330 & 495 \\
\hline Percentage Growth & & 23 & 26 & 38 & 50 \\
\hline
\end{tabular}


TABLE 2.7. Price Range for Robots $(1981)^{\text {(a) }}$

(Baranson 1983)

\begin{tabular}{|c|c|}
\hline Country & Price Range (U.S. \$ \\
\hline United States & $\$ 10,000-\$ 150,000$ \\
\hline Japan & $\$ 6,825-\$ 100,000$ \\
\hline \multicolumn{2}{|l|}{ Europe } \\
\hline West Germany & $\$ 13,200-\$ 123,200$ \\
\hline United Kingdom & $\$ 17,400-\$ 110,400$ \\
\hline Sweden & $\$ 8,860-\$ 90,000$ \\
\hline Norway & $\$ 8,519-\$ 85,175$ \\
\hline France & $\$ 4,000-\$ 160,000$ \\
\hline Italy & $\$ 10,000-\$ 150,000$ \\
\hline
\end{tabular}

(a) RIA definition of robot excludes mechanical transfer devices.

and comfort. In automobile painting, for example, humans have had to work with masks in surroundings permeated with toxic paints, or firms have had to use more expensive, nontoxic paints with extensive space conditioning systems. The use of painting robots allows the operation to occur in an enclosed environment with greatly reduced paint and space conditioning costs.

The use of robots can also provide a more reliable production system. The performance of the robots is designed to be consistent, preventing production fluctuations caused by more variable human performance, which can lead to phenomena such as the "Monday car" syndrome in the automobile industry.

The overall productivity of industries can be enhanced by other advantages robots offer, such as the possibility of operating 24 hours a day and reduced needs for space heating, air conditioning or lighting. Even when robots are only used for normal operating hours, productivity can increase. For example, in Chrysler's Jefferson plant, 200 human welders on an assembly line were replaced by 50 robots. These robots worked two shifts per day and the assembly line's output increased by $20 \%$. 
Unimation and Cincinnati Milatron estimated that in 1983 the cost of operating an industrial robot was \$5-6/per hour, which compared with an equivalent labor cost of $\$ 17-30$ per hour (Baranson 1983).

Projections for the growth of robots were very optimistic in the late 1970s and early 1980s, with projections of 30-40\% annual increases in sales and with markets as large as $\$ 40$ billion by 2000 . To date, however, the growth of robots has not achieved this promise. Reasons for the slower growth include the general recession of the early 1980s, reduced purchases of robots by automobile manufacturers, the priority purchases of computer-aided design and manufacturing resource planning systems instead of robots, and the longer than anticipated implementation time for custom application of robots.

Growth projections to 1990 show the sales of robots increasing $30-40 \%$ (Baranson 1983). Using the lower figure of 30\%, the market in 1990 is expected to reach $\$ 1.5$ billion, with about 15,000 units expected to be sold. If this growth continues to the year 2000, the robot market is predicted to grow to $\$ 20$ billion (Fredkin 1984 and Zeldman 1984).

\subsection{TRIBOLOGICAL LOSSES IN THE ROBOTICS INDUSTRY}

The use of robots in industry is affected by several significant tribological sinks. Most of the concern with tribological effects among manufacturers and users, however, is related to reliability, speed, and precision, rather than energy use. Robots become attractive to potential users if they operate reliably, and if their speed and precision are high enough to ensure efficient operation. For example, the most common cause of robot failure is the wear of parts (Cowick 1985). Tribological improvements could offer important contributions to more efficient and reliable operation of robots, as well as saving energy from direct and indirect losses.

Major sources of tribological wear in the robotics industry include the chains caused to drive the robots, and the bearings, ball screws, and gears used in the shoulder, elbow, and wrist joints of the robot. The lubricants used to reduce wear in these parts are suboptimal for many applications, and frequent maintenance is usually required. The principal wear mechanisms for both chain drives and wrist and elbow joints are friction and abrasion. 


\subsubsection{Direct Energy Losses in the Robotics Industry}

In the operation of robots, the direct energy loss due to friction and abrasion is estimated by robot manufacturers to be fairly low. This is because the bearings that are currently available for the joints provide high mechanical efficiencies. Overall robot efficiency is estimated to range from 90-95\%. The maximum amount of direct energy consumption that could be saved from reducing tribological sinks was therefore estimated to be about $5 \%$. For example, in 1983, robots consumed approximately $1.8 \times 10^{12}$ Btu of fuel (in the form of electric energy); the maximum direct energy savings that would be possible would therefore be about $9 \times 10^{10}$ Btu/year. Maximum direct energy savings possible in the robotics industry are summarized in Table 2.8. The cost of energy lost at $5 \$ / \mathrm{kWh}$ is also shown in this table. The result is that the cost of energy lost is expected to rise from about $\$ 435,000$ in 1983 to over $\$ 7,000,000$ in 2000 .

\subsubsection{Indirect Energy Loss}

A typical industrial robot's lifespan is 40,000 hours of operation, which translates to seven years of service at two shifts per day. The largest tribological components, such as the waist bearing or large shoulder bearings, are usually designed to last for the life of the robot. Although tribological improvements may increase robot service time, there are often elements such as corrosion and metal fatigue that also limit the ultimate life. This analys is of embodied energy will focus on current requirements of robot operation and maintenance and will take credit for the uncertain extension of robot life. It should be recognized, however, that increased service time from improvements

TABLE 2.8. Direct Energy Losses and Costs in the Robotics Industry

$\begin{array}{lcccc}\text { Year } & \begin{array}{c}\text { Total Direct Energy } \\ \text { Btu/yr }\end{array} & \begin{array}{c}\text { Tribological Losses } \\ \text { Btu/yr }\end{array} & \begin{array}{c}\text { Cost of } \\ \text { Energy Lost } \$\end{array} \\ 1983 & 1.8 \times 10^{12} & & 9.0 \times 10^{10} & 1.45 \times 10^{5} \\ 1990 & 2.3 \times 10^{12} & & 1.1 \times 10^{11} & 5.32 \times 10^{5} \\ 2000 & 2.9 \times 10^{13} & & 1.5 \times 10^{12} & 7.25 \times 10^{6}\end{array}$


that lessen tribological effects would clearly have some impact on reducing indirect tribological losses since the entire unit would not have to be scrapped as frequently.

The regular maintenance and replacement of parts for reliable and precise operation of robots require that lubricants be regularly changed and that certain components periodically replaced. Both forms of required maintenance are caused by the need to minimize tribological inefficiencies. Common forms of lubricant maintenance include changing the hydraulic oil and grease. Common components needing periodic replacement include the drive chains and the wrist and arm joint bearings.

Normal maintenance calls for periodically replacing hydraulic fluid to maintain desired fluid characteristics. A typical schedule might call for replacement every 1,000 hours of operation. Assuming an average size of 10 gallons for the hydraulic fluid reservoir, the annual energy loss that is embodied in the fluid was approximately 25.7 billion Btu in 1983. Using the robot use projections presented earlier, the embodied energy loss is estimated to be 36.4 billion Btu in 1990 and 76.5 billion Btu in 2000 .

Periodic replacement of parts due to friction and wear also results in an embodied energy loss. Chains are typically used as drives in translating force because of their low cost and ease of use. However, with use the chain rollers wear from contact with the gears and the chains stretch, reducing the degree of control over the movement of the robot. Chains are typically replaced every 5,000 to 10,000 hours of operation. The embodied energy lost through chain replacement was estimated to be 1.81 billion Btu in 1983, and is estimated to be 2.52 billion Btu in 1990 and 19.0 billion Btu in the year 2000 .

Smaller bearings that experience a large part of the motion of robots, such as those in the wrist, are replaced every 5,000 to 12,000 hours of operation. Using a rough estimate for the replacement of elbow and wrist bearings, 0.848 billion Btu of embodied energy were estimated to be lost in 1983, with 1.35 billion Btu of estimated loss in 1990 and 18.0 billion Btu in 2000 . 
The indirect energy losses described above are summarized in Table 2.9. Although the figures presented above are only very approximate estimates, they do reveal that embodied energy losses in robots are not expected to be significant through the end of this century. Research can certainly reduce the losses that are projected, but the energy savings due to tribological improvements in robotics are not likely to be notable.

\subsubsection{Productivity and Monetary Losses}

Monetary losses in the robotics industry from the energy and materials losses due to tribology are relatively small at the present time. The largest single cost in 1983 was for the replacement of worn chains, estimated to have cost approximately $\$ 3$ million. (a) By the year 2000 , the cost of worn chain replacement is expected to rise to over $\$ 30$ million, with worn bearing replacement also a significant cost at $\$ 12$ million. The cost of replacing hydraulic 011 was estimated to be only $\$ 400,000$ in 1983 , rising to $\$ 1.2$ million dollars by 2000 .

The additional energy required because of tribological losses has a smaller cost than the materials replacement costs. Assuming an electricity cost of $\$ 0.05 / \mathrm{kWh}$ (Miedema and Stern 1985), then the total direct energy losses would have cost $\$ 430,000$ in 1983 , rising to $\$ 7.2$ million by 2000 . Indirect energy losses would have cost $\$ 130,000$ in 1983 , rising to $\$ 550,000$ by 2000 . Total costs due to energy losses were $\$ 560,000$ in 1983 , and rising to $\$ 7.8 \mathrm{mil1}$ ion by 2000 .

Total economic losses associated with direct energy and materials losses are shown in Table 2.10. The total economic losses are expected to rise from $\$ 4.4$ million in 1983 to $\$ 51$ million in 2000 . Monetary costs of completely replacing robots has not been included.

The three major tribological concerns in the robotics industry are:

1) reliability, 2) speed, and 3) precision. Each area of concern also involves indirect energy losses due to material wear. Improvements in these areas would greatly increase robot productivity.

(a) Estimates of electricity use for these cost calculations assume a Btu equivalent of $3.413 \times 10^{3} \mathrm{Btu} / \mathrm{kWe}$. 
TABLE 2.9. Indirect Energy Losses Due to Tribology in the Dperation of Robots

$\begin{array}{lllll}\text { Indirect Energy Loss } & \frac{1983}{\text { Btu }} & \frac{1990}{\text { Btu }} & \frac{2000}{\text { Btu }} \\ \begin{array}{l}\text { Hydraulic 0il } \\ \begin{array}{l}\text { Energy Embodied in } \\ \text { Replaced Chains }\end{array}\end{array} & 1.81 \times 10^{9} & 2.52 \times 10^{9} & 19.0 \times 10^{9} \\ \begin{array}{l}\text { Energy Embodied in } \\ \text { Replaced Bearings } \\ \quad \text { Total }\end{array} & \frac{0.848 \times 10^{9}}{36.4 \times 10^{9}} & \frac{1.35 \times 10^{9}}{76.5 \times 10^{9}} & \frac{18.0 \times 10^{9}}{1.0 \times 10^{10}} & \frac{4.0 \times 10^{10}}{1.1 \times 10^{11}}\end{array}$

TABLE 2.10. Tribological Monetary Losses in the Robotics Industry

\begin{tabular}{|c|c|c|c|}
\hline & Monetary & Losses, & $\$ 10^{6} / y r$ \\
\hline Item & 1983 & 1990 & 2000 \\
\hline Hydraulic oil & 0.40 & 0.57 & 1.20 \\
\hline Replaced chains & 2.90 & 4.03 & 30.50 \\
\hline Replaced bearings & 0.56 & 0.90 & 12.00 \\
\hline \multicolumn{4}{|l|}{ Energy costs } \\
\hline Oirect & 0.43 & 0.53 & 7.25 \\
\hline Indirect & $\underline{0.13}$ & $\underline{0.20}$ & 0.50 \\
\hline Total & 4.42 & 6.23 & 51.45 \\
\hline
\end{tabular}

Lack of reliability is usually caused by problems in one or more of the following four areas: the motion of the robot arm, slow and/or intermittent operation, the generally poor match between lubricants and parts, and the operational environment. The motion of the robot arm takes place through a variety of angles along several axes. This motion is particularly extensive for robot painters, and at the wrist joints of both painters and assemblers. As a result of this motion, the lubrication is often improperly distributed at the interfaces of the chains and gears that provide the motion. This suboptimal lubrication causes the parts to wear more quickly than they would in a properly lubricated system. Some form of lubrication is needed that will stick 
to the surfaces of the moving parts while providing friction reduction. Possible improvements include using a solid lubricant, providing better surface film control, and modifying the surface completely.

Excessive bearing wear can also result from the intermittent, oscillatory, or continuous low speed of many robots, especially if the lubricant is not adequately and continuously supplied to the raceways and roller-element separators. This excessive wear could be reduced by modifying bearing surface finishes, bearing geometry, or component materials, and by the use of special surface coatings and lubricants.

Other highly stressed robotic components that would benefit from more appropriate lubricants are chains and ball screws. Chains are frequently used to transmit actuating force from joint to joint, because they are easy to use and inexpensive. However, chains tend to wear and stretch at the gear interface, reducing the precision of control over the robot. Ball screws are corimonly used gears in the shoulder and elbow joints of the robot, and wear of the bearings in the ball screw adversely affects the robot's reliability. Both chains and bearings must be frequentily replaced; chains typically operate for 5,000-10,000 hours, and bearings for 5,000-40,000 hours. Grease is currently used to lubricate the chains, but its suboptimal viscosity may lead to chain seizure. Lubricants that are not prone to leakage are needed for both of these applications.

In harsh environments, robots are often an immediately attractive alternative to human labor. However, these environments can be just as hostile to robots. For example, spray painting booths create a hostile environment in which robots must operate. The solvents and chemicals present can attack metallic parts, painted surfaces, and protective covers. Furthermore, the abrasive pigments and the metallic particles erode bearing surfaces and destroy elastomer seals and boots. Aggravating this problem is the water wash spray used to collect "over spray." A variety of chemicals is used to neutralize the binding resins of the paints. These chemicals also remove grease and oils from unprotected areas of the robot. Robot operation in harsh environments would benefit from materials resistant to corrosion and abrasion. 
The second area of concern for the users and manufacturers of robots is improving the speed of robot operations such as painting, assembling, and welding. Speed is limited by inertial and kinematic factors that are in turn related to the mass of the robots' components. One of the most effective ways to reduce the mass of the robots is to reduce the bearing weight. It has been estimated that every pound saved in bearing weight results in a reduction of almost ten pounds in structural weight (George 1983). Lighter bearings or bearing systems would thus result in more responsive systems, materials savings, and reduced power requirements.

The third area of concern in the robotics industry is precision. The ability to precisely control the robot stems from a combination of electronic and/or computer control, and the mechanical precision of the part. Most new robot systems are closed-loop, self-controlled, self-diagnosed installations. If spatial errors are not detected, excessive scrap can be produced. In the mechanical system, major problems stem from the bearings at the pivot points, the manipulator wrists, and the drive transmission. For example, the arm and wrist joints in painter robots will result in sloppier movement over time due to frictional wear.

Imprecision in the joints of the robot can be very significant because errors are often amplified at the gripper. For example, bearing positioning errors at the waist of the robot can become magnified as the extended robot arm moves through a long arc; a 0.005 inch deviation at the waist may be magnified to a 0.050 inch variation at the gripper (George 1983). Methods of increasing rotational accuracy include increasing the bearing stiffness, controlling bearing play, and using tightened manufacturing tolerances. However, additional problems of wear can result from the production techniques used to increase bearing stiffness. For example, one method of increasing accuracy is to increase the frictional torque at the joint by preloading; this can cause slight increases in power requirements, although torque uniformity is often more important than torque magnitude.

Tribological advances can benefit the robotics industry in other ways in addition to addressing the concerns of reliability, speed, and precision. Two areas that could be aided by tribological advances are the operation of robots 
in specialized environments such as clean rooms, and the development of alternative robot designs that have added lubrication requirements. In clean rooms, lubricants such as the oil or grease used in robots can be a serious contaminant due to leakage. Dry lubricants or surface coatings would allow increased use of robots in clean rooms. Alternative robot designs that provide features such as greater flexibility or greater efficiency can pose additional tribological challenges. The snake-like, spined robot, which offers extensive flexibility in its motions, also poses significant tribological challenges because of its multiple spine joints. Electrically-driven robot painters offer a more efficient alternative to the conventional hydraulic designs. Electricallydriven robot painters have lower power consumption, lower weight (and faster response), and lower cost. However, new seals are needed between the motor anc the lubricant/gear system, since improper sealing can burn out the motor. A solid or dry lubricant or surface treatment would be required.

\subsection{SUMMARY OF TRIBOLOGICAL SINKS IN THE ROBOTICS INDUSTRY}

The robotics industry is a relatively small energy consumer, although consumption is expected to rise as the use of robots increases. Robotics consumed a total of $1.8 \times 10^{12} \mathrm{Btu}$ of electrical energy in 1983 , assuming a $33 \%$ conversion efficiency. By the year 2000, the robotics industry is expected to consume about $3.0 \times 10^{13} \mathrm{Btu} /$ year of electrical energy. Direct energy losses due to tribology are relatively small, because the mechanical systems are already highly efficient; they have the ability to convert 90-95\% of the electricity used into useful work. The maximum anount of improvement in energy efficiency would therefore be about $5 \%$. This translates into a maximum direct energy savings of $9 \times 10^{10} \mathrm{Btu} /$ year in 1983, and an estimated maximum direct energy savings of $1.5 \times 10^{12} \mathrm{Btu} /$ year in 2000 , due to removal of tribological sinks.

Indirect energy losses due to tribological sinks are also relatively sma11. The principal losses occur in the embodied energy in the oil and grease lubricants, and in replacement items such as drive chains and wrist and elbow bearings. Replacement of the hydraulic fluid resulted in an estimated embodied energy loss of $25.7 \times 10^{9} \mathrm{Btu}$ in 1983 , projected to increase to $76.5 \times 10^{9} \mathrm{Btu}$ 
in 2000. Embodied energy loss due to replacement of the chains and bearings is estimated to have been about $2.7 \times 10^{9}$ Btu in 1983 , and will increase to $3.7 \times$ $10^{10}$ in 2000 .

Monetary losses due to materials replacement are higher than the monetary losses due to direct and indirect energy 10ss. The total monetary losses from both materials and energy loss were estimated to be $\$ 4.4$ million dollars in 1983, rising to 51 miltion dollars in the year 2000.

From the perspective of the robot manufacturer and user, the significance of tribology relates to issues of productivity such as reliability, speed, and precision. For example, reducing the frequency of required maintenance or of unexpected failures will become increasingly important as robots are used in more continuous operations. Reducing the weight of bearings and the lubrication systems will have an amplifying effect on weight savings in the robot arm, with a consequent increase in the speed of the system's response. Increasing the wear-resistance of bearings would maintain the precision of robot movements while reducing the need to replace parts because of increased inaccuracies. 



\subsection{TRIBOLOGICAL ENERGY LOSS IN THE ELECTRONICS INDUSTRY}

This chapter identifies and characterizes total energy use and tribological losses in the electronics industry. Energy consumption is specified by fuel type for the major electronics sectors. The major processes and products of the electronics industry are described, and the few processes identified as having tribological losses are described in more detail. Finally, the nature of each tribological sink and the mechanisms leading to direct or indirect losses are characterized, and qualitative estimates of energy losses are made.

\subsection{THE ELECTRONICS INDUSTRY}

The electronics industry, as defined by the Standard Industrial Classification Manual, is composed of businesses that manufacture electronic components and accessories (SIC 367). Included under this category are electron tubes (SIC 3671), semiconductors (SIC 3674), electronic capacitors (SIC 3675), electronic resistors (SIC 3676), electronic coils and transformers (SIC 3677), electronic connectors (SIC 3678), and other electronic components (SIC 3679). This report is primarily concerned with semiconductors and other electronic components (SIC 3674 and 3679), because they are the two largest energy consumers in the electronics industry. In fact, these two subcategories account for nearly three quarters of the total energy consumed by the electronics industry.

\subsection{TOTAL ENERGY USE IN THE ELECTRONICS INDUSTRY}

Total energy consumption in the electronics industry was $52.5 \times 10^{12}$ in 1981. (a) The energy consumption for each subcategory is shown in Table 3.1 .

The most important sources of fuel for the electronics industry are purchased electricity and natural gas. Tables 3.2 through 3.4 list the energy consumption, by type of fuel, for the electronics industry as a whole and for two of its subdivisions.

(a) All estimates of electricity use assume a Btu equivalent of $3.413 \times 10^{3}$ Btu/kWe. 
TABLE 3.1. Energy Consumption in Electronics(a)

\begin{tabular}{|c|c|c|c|}
\hline SIC & Classification & $10^{12} \mathrm{Btu} / \mathrm{yr}$ & $\%$ of Total \\
\hline 3671 & Electron tubes & 6.9 & 13 \\
\hline 3674 & Semiconductors & 20.9 & 40 \\
\hline 3675 & Electronic capacitors & 3.1 & 6 \\
\hline 3676 & Electronic resistors & 1.4 & 3 \\
\hline 3677 & Coits and transformers & 0.8 & 1 \\
\hline 3678 & Electronic connectors & 2.2 & 4 \\
\hline \multirow[t]{2}{*}{3679} & Other electronics & $\underline{17.1}$ & 33 \\
\hline & Total & 52.5 & 100 \\
\hline
\end{tabular}

(a) Due to rounding assumptions, totals indicated may be slightly different than the sum of the columns.

TABLE 3.2. Energy Consumption by Fuel Type in the Electronics Industry

\begin{tabular}{lccc}
\multicolumn{1}{c}{ Fuel } & $\frac{10^{12} \mathrm{Btu} / \mathrm{yr}}{28.2}$ & & \% of Total \\
\cline { 1 - 1 } Electricity & 1.23 & & 54 \\
Distillate 0il & 2.52 & 5 \\
Residual 0il & 13.8 & 26 \\
Natural Gas & 0.12 & 0.2 \\
Liquefied Petroleum Gas & $\underline{6.63}$ & $\underline{13}$ \\
Other (or not specified) & 52.5 &
\end{tabular}

TABLE 3.3. Energy Consumption by Fuel Type for Semiconductor Manufacture

\begin{tabular}{|c|c|c|c|}
\hline SIC & Fuel & $10^{12} \mathrm{Btu} / \mathrm{yr}$ & $\%$ of Total \\
\hline \multirow[t]{7}{*}{$\overline{3674}$} & Electricity & 13.88 & 66 \\
\hline & Distillate 0il & 0.28 & 1 \\
\hline & Residual Dil & 0.66 & 3 \\
\hline & Natural Gas & 4.97 & 24 \\
\hline & Liquefied Petroleum Gas & $\rightarrow$ & -- \\
\hline & Other (or not specified) & 1.19 & 6 \\
\hline & Total & 20.9 & 100 \\
\hline
\end{tabular}


TABLE 3.4. Energy Consumption by Fuel Type for "Other Electronics" Category

\begin{tabular}{|c|c|c|c|}
\hline SIC & Fuel & $10^{12} \mathrm{Btu} / \mathrm{yr}$ & $\%$ of Total \\
\hline \multirow[t]{7}{*}{$\overline{3679}$} & Electricity & 7.40 & 44 \\
\hline & Distillate $0 i 1$ & 0.58 & 3 \\
\hline & Residual 0il & 0.6 & 3 \\
\hline & Natural Gas & 4.35 & 26 \\
\hline & Liquefied Petroleum Gas & 0.02 & -- \\
\hline & Other (or not specified) & 4.15 & 24 \\
\hline & Total & 17.10 & 100 \\
\hline
\end{tabular}

\subsection{PROCESSES IN THE ELECTRONICS INDUSTRY}

A long series of processing steps are required to produce the complex products characteristic of the electronics industry. Descriptions of these process details will be grouped into general categories for this discussion.

\subsubsection{Monocrystalline Silicon Production}

Ultrapure monocrystalline silicon manufacture is the first processing category. Metallurgical grade silicon is first produced from the reduction of silicon oxide in electric-arc furnaces at $2000^{\circ} \mathrm{C}$ (Labuda and Clemens, 19B2). Production of metallurgical grade silicon is not usually considered to be a part of the electronics industry, since it is used as starting material. The metallurgical grade silicon is pulverized and reacted with hydrogen chloride in a fluid-bed reactor at $350^{\circ} \mathrm{C}$, producing trichlorosilane which is further refined by distillation. The trichlorosilane is reduced with hydrogen on a resistance-heated thin rod of high-purity silicon at $1100^{\circ} \mathrm{C}$, yielding highpurity polycrystalline silicon (Labuda and Clemens 1982, Larrabee 1985).

To convert polycrystalline silicon to monocrystalline silicon, most manufacturers use Czochralski crystal-growth techniques. The polycrystalline silicon is melted in a quartz crucible at approximately $1500^{\circ} \mathrm{C}$, a single crystal seed is introduced, and the crystal is pulled from the melt (Larrabee 1985). The quartz crucibles have short lifetimes; often they must be replaced after 4-5 crystal ingots have been produced (Kayex 1981, Daud and Kachare 
1982). Typical crystals are usually between 4 and 6 inches in diameter (Larrabee 1985), and weigh 30-40 pounds, depending on length (Kayex 1981). Worldwide production of polycrystalline silicon in 1984 was about 45005000 metric tons; production of semiconductor grade monocrystalline silicon was about 3200 metric tons in 1982 (Larrabee 1985, Labuda and Clemens 1982). Production of monocrystalline silicon is an energy-intensive process; the processing step with the highest energy consumption per unit of production is the purification of silicon from metallurgical grade material. Details of energy use will be discussed in the next section.

\subsubsection{Wafer Production}

The second category of operations, after producing the monocrystalline silicon, is producing wafers from the crystal. Wafers are prepared by first sawing the crystal into thin slices, mechanically lapping, and then cleaning and polishing the slices by some variation of chemical/mechanical techniques (Larrabee 1985, Labuda and Clemens 1982). Slicing is usually done with an inner-diameter saw, in which the stationary ingot is passed through the inner space of an annular cutting blade (ID blade). This blade is a thin, circular steel membrane with a large central hole; the inner edge is coated with electroplated diamond-nickel. The blade core is made of cold-rolled steel. The blade rotates at high speed, abrasively grinding the silicon into thin slices (Mokashi 1982, Lane 1985). The silicon ingot is held in a mounting device with the use of adhesives. Although the adhesive is necessary for slicing control, it contaminates the diamond/nickel matrix at the blade edge. Frequent dressing of the blade with soft silica is required to reduce wafer damage. Cutting fluids, usually water-based, function as both lubricants and coolants for the grinding process (Lane 1985).

The trend towards larger diameter ingots has increased requirements for high blade rigidity and minimum vibration. Improvements in blade life resulting from decreased adhesive loading in the diamond/nickel matrix are also expected in the future (Jacksen 1985).

Materials loss is a problem, since the blade is nearly as wide as the slices cut (Mokashi 1982). The material loss due to blade displacement is 
known as kerf. Kerf losses per slice increase as the diameter of the silicon ingot increases, because the larger blades require thicker core material. A typical silicon ingot with a six-inch diameter would have a kerf loss of 0.015 inch (thickness) per slice (Lane 1985); each slice would be about 0.02 inches thick (Jacksen 1985). Other slicing methods such as rotating the silicon ingot, and using diamond encrusted wire or multiblade wafering, have so far proved unsatisfactory for electronics-grade silicon. I0 slicing is still preferred due to its straight cuts, and uniformity of slice thickness.

After the wafers are sliced, they are double lapped with a free abrasive to reduce damage caused by slicing. The wafer is situated between two lapping wheels to ensure that damage will be equalized on both sides of the wafer, reducing stress. Lapping reduces the damage thickness from 15-20 microns to 5 microns, which is further reduced by polishing. Polishing is accomplished with an alkaline slurry containing a very mild abrasive such as colloidal silica. The wafer is etched with the alkali and lightly abraded with the silica. After polishing, the wafer is cleaned with peroxysulfuric acid to oxidize organic materials, and with aqua regia to remove metals. The final step involves annealing the wafers in an inert gas oven to remove interstitial oxygen (Chang 1982, Jacksen 1985).

Energy requirements for wafer production are relatively small; the total energy costs are only 1 or 2 percent of the equipnent and materials costs (Mokashi 1982). However, in an increasingly competitive market, energy requirements are becoming more important to manufacturers. Most wafer manufacturers are now located in areas with less expensive electricity. (a) Direct energy consumption for wafer production from silicon ingots is primarily required for slicing and lapping rather than for chemical polishing. Better control of the wear that is necessary during slicing and lapping would reduce both the direct energy requirements and materials losses.

Materials losses contribute significantly to the cost of wafer production. For example, kerf losses can amount to as much as $40 \%$ of the total

(a) Telephone conversation with Niels Jacksen, Optoelectronics, January 1986. 
volume of the silicon ingot--and silicon ingots cost $\$ 40 / \mathrm{kg}$ (Jacksen 1985, Lane 1985). Of the remaining material, there are wafer losses of 5-10\% due to exit chipping and other induced damage. The blades have a lifetime of about 2000 slices, assuming that they are properly maintained and tensioned, (a) and they cost about $\$ 120$ each. If the blade life is assumed to be 2000 slices, and the yield of wafers (excluding kerf loss) is $90 \%$, the add-on cost will be about $\$ 13$ per square meter of silicon crystal sliced for the materials alone. (b)

\subsubsection{Integrated Circuit Production}

The next operational category involves manufacturing integrated circuits (ICS) on the wafer. IC manufacture begins with the development of the integrated circuit design, using computer aided design tools. The IC designs are used to do a layout of the circuits, and then photomasks are designed and fabricated. Today, most photomasks are made from quartz plates with a thin film of chromium on the surface. Mask patterns are generated with electron-beam exposure (Labuda and Clemens 1982), which provides good resolution and control of edges. Multiple masks are used for device fabrication. The information from the masks is usually transferred to the wafer via photolithography.

A layer of silicon dioxide is generated on the silicon wafer by oxidation in horizontal resistance furnaces operated at $900-1200^{\circ} \mathrm{C}$. The silicon dioxide acts as a substrate for the various layers of photoresists and dopants which are needed to build the circuit. Then the wafer is coated with a photoresist, and a light source is shown through the photomask. This will make certain parts of the photoresist susceptible to chemical attack, so etchants can remove the activated photoresist.

The etching has been traditionally done with wet chemicals which dissolve one material preferentially over another. However, plasma etching is rapidly being substituted for this step, primarily because it provides finer line definition and greater directional control (Fonash 1985, Pogge 1985). Line widths in integrated circuits have been halved every six years, and are expected to be

(a) Telephone conversation with Silicon Technology Corporation representative, August 1985.

(b) Telephone conversation with Niels Jacksen, Optoelectronics, January 1986. 
one micron wide by 1990 (Stover 1985). Plasma etching involves bombarding a substance with chemical ions to form volatile species, which can be removed with a vacuum pump. The most effective plasma etching uses both chemical and physical mechanisms to remove material with great specificity. The vacuum can range from $10^{-3}$ torr to $10^{1}$ torr, depending on operating conditions (Fonash 1985). The exposure of photoresist to light through the mask, and subsequent preferential etching, is referred to as photolithography. A series of photolithography steps are needed to transfer the circuit design to the wafer. In the more distant future, light exposure and chemical or plasma etching will probably not be used at all, since the lowest possible resolution 1 imit is about half a micron (Wilson 1986). Lithography will probably be done directly on the wafer, using either electron beams or x-rays (Guterl 1984, Wilson 1986).

After each etching step, a dopant or other chemical film is deposited. Doping is required for transforming the silicon into a semiconductor. Atoms such as boron are implanted to allow the transfer of charge. Doping can be done by deposition, implantation, or molecular beam epitaxy. The film between layers of dopant is usually deposited by chemical vapor deposition (CVD), in which a chemical synthesis occurs in the vapor phase to form a solid product that deposits as a film on the substrate (Pogge 1985). CVD is usually done under vacuum, partly to increase the vapor pressure of reactants and partly also to improve uniformity of deposition (Kurnik 1985). Materials routinely deposited include silicon, silicon dioxide, and several different metals (Kurnik 1985). The last deposition made is of metal.

A typical process scheme currently in use for a metal-oxide semiconductor might be as follows: After growing a layer of silicon dioxide, silicon nitride is deposited and patterned with a photomask. Boron is implanted in the areas available after patterning. The nitride mask is removed. Then a layer of polycrystalline silicon is deposited, doped with phosphorus, and patterned. Next, the gate oxide is grown via oxidation of available polycrystalline silicon. A second polycrystalline layer (which is also the gate material) is deposited, patterned, and doped with arsenic. After the arsenic glass is removed, the exposed silicon areas are oxidized. An insulating layer of oxide is deposited, 
and contact windows are defined by photolithography and etching. Aluminum is deposited by electron-gun evaporation to allow for transfer of current at the contacts.

After the circuits have been inscribed, the wafer is passivated to protect it from contamination during bonding pad formation. Bonding pads are a part of the electrical connections between the chip and the rest of the device. A bonding pad is formed from the deposition of several different layers of metal, including titanium, platinum, and gold. Gold is needed as a corrosionresistant cover, and as an easily bonded conductor. A combination of physical and chemical methods is used to pattern the stack of different metals. After formation of the bonding pad, the wafers are optically inspected and separated into chips.

Most wafers are separated by dicing with diamond-impregnated wheels. Scribing, either by lasers or with diamonds, gives lower yields and also requires a subsequent breaking operation. The dicing wheels have wear problems similar to those of the annular blades used for silicon ingot slicing. Wear in the wheel rims causes wafer chipping and reduced blade life. It can be mitigated by the use of coolant, reduction of vibration, and frequent alignment and dressing of the blade (Gariepy 1985).

After separation, the bonding pads on the chips are electrically connected to the pins on the chip supports. These connections can be made with wire bonding, currently the most widely used method (Harman and Gettinger 1985), or with beam leads or conducting epoxy. Tape automated bonding, in which the conductor pattern is plated on plastic tape and compressed onto the bonding pads, may be used more widely in the future. The conducting elements generally contain goid because of its high ductility and conductivity. Finally, the assembly is molded in plastic and/or sealed, and tested (Chang 1982). Inspection is usually done with the "bright light" technique, but laser wafer scanners are also used.

Semiconductor production is carried out in clean rooms with exacting specifications, since particles smaller than a micron can destroy a microcircuit. A current state-of-the-art clean room contains about 10 particles larger 
than 0.2 microns per cubic foot of air; by comparison, normal urban air contains more than a million particles per cubic foot (Larrabee 1985). To achieve this cleanliness, the air flows through thick particle absorption filters. These filters may be electrostatically enhanced in the future, as particles currently too small to be caught by conventional filters become a problem for ever-smaller circuits (Hoenig 1985). Floors are covered with sticky mats for particle entrapment, and personnel wear masks and special skin coverings. Laminar air flow must be provided over wafer processing areas to sweep particles away quickly.

Many of the sequential steps in the clean rooms are performed without human intervention for reasons of cleanliness as well as reliability. For example, during photolithography, the wafers move along on an air track. They are picked up with a vacuum system that contacts the back side only, and can be transferred by robot to other work stations. Automated processes can also include spinning the polymer onto the wafer, diffusion furnace heating, optical exposure, and developer spraying. Robot wafer handling systems have been shown to be up to ten times cleaner than human handling systems, even though the robots generate particulates and organic vapors (Hoenig 1985). In fact, as processing becomes more automated and as other sources of particle contamination are cleaned up, the process equipment has become a major source of particulate defects on wafers (Burnett 1985).

\subsubsection{Circuit Board Assembly}

The final category of operations involves assembling the chips onto printed circuit (PC) boards for use in computers, telecommunications equipment, automobiles, and other items which include electronic components. Individual $P C$ boards can fulfill such functions as signal processing; when connected into sub-assemblies, they can control such functions as memory, analog input-output, and math. The PC boards take the place of bundles of loose wire commonly used to make connections twenty years ago. Most PC boards are single-or doublesided. Although it is possible to make multilayer PCs, the processing is very expensive; they are used only for specialized applications such as high-speed switching. 
Production of PC boards has some similarities to the production of integrated circuits. PC board processing begins with artwork preparation, in which the board circuits are designed. The board begins with a base layer of epoxy glass, with a layer of copper on top. The circuits are transferred to the copper via photolithography and etching. Holes for the pins of the components are drilled, deburred, and plated through (although surface-mount technology may one day take the place of plated-through holes) (Lau and Rice 1985). After shielding the rest of the board, gold is then electroplated from solution onto the locations where there will be edge or sliding contacts (e.g., at the sockets). Gold is preferred for sliding contacts because of its conductivity and resistance to corrosion or chemical attack. The next step is to attach the components to the circuit board. The component pins are inserted into the plated-through holes, and then are soldered into place. A layer of plastic protects the rest of the board from the solder. Finally, the circuit board is tested and repairs are made if necessary. (a) Although clean rooms have not been used as much in the past for PC board assembly, they are becoming necessary as the circuits become smaller and more susceptible to damage by small particles (Ford 1985).

\subsection{PROCESS ENERGY CONSUMPTION}

The information about the energy requirements for these processing steps varies; detailed energy requirements are available for aspects of silicon wafer production, but very little energy information is available for integrated circuit or printed circuit board manufacture. The reason for this disparity is that the photovoltaic (PV) industry also uses wafers cut from silicon crystals as a starting material. If photovoltaics are to be economical, the cost of the silicon wafers in the cells must be reduced. PV manufacturers have studied reducing energy consumption as a method of cost control, and the results are publicly available. Although there is much less public evidence, the manufacturers of electronics-grade silicon wafers may also concerned about energy

(a) Telephone conversation with J.T. Russell, Vice President of Optical Recording Corporation, June 1986. 
costs, even though many of them are located in the Pacific Northwest, where electrical rates are low.(a)

Manufacturers of integrated circuits and PC boards have not published energy consumption information, and production engineers interviewed regarded this information as proprietary. However, these engineers did indicate that energy conservation is not an important priority, since energy costs are only a small percentage of overall costs. $(b, c)$ There are efforts underway to reduce the energy consumption of the completed chip, since power dissipation has become a limiting factor to operational speed (Keys 1985).

Energy consumption for each major step in the production of silicon wafers is divided into several categories. Direct energy consumption refers to the energy needed for heating, fluidizing, distillation, and running the pulling and slicing machines. Indirect energy consumption refers to the energy required to produce the materials that are consumed, such as hydrochloric acid, hydrogen, quartz crucibles, slicing blades, inert gases, and electrodes. Mining and transportation energy are included for mining the quartzite ore used as the starting material for metallurgical grade silicon, and for transporting the ore to the refinery. Equipment and overhead energy consumption represent the energy embodied in equipment investments and overhead operations. Table 3.5 lists energy consumption, by category, for each major manufacturing process for silicon wafers (Lindmeyer et al. 1977).

Table 3.6 summarizes the results of Table 3.5 and compares the energy consumption of each process step with the total energy consumption for semiconductors and for the whole electronics industry.

As shown, the production of electronics-grade silicon wafers requires almost half of the energy required by the semiconductor industry as a whole, and about $19 \%$ of the energy required by the entire electronics industry.

(a) Telephone conversation with N. Jacksen, Optoelectronics, January 1986.

(b) Telephone conversation, July 1985, with J. Rabinowitz, engineer at Floating Point, Portland, Oregon.

(c) Telephone conversation, July 1985, with G. Stipe, facilities engineer at Inte1, Hillsboro, Oregon. 
TABLE 3.5. Energy Consumption for Silicon Wafer Production

\begin{tabular}{|c|c|c|c|}
\hline Operation & $\begin{array}{c}\text { Energy/unit, } \\
\text { Btu } / \mathrm{kg} \text { Produced }\end{array}$ & $\begin{array}{c}\text { Quantity, } \\
\mathrm{kg}\end{array}$ & $\begin{array}{c}\text { Total Energy } \\
\text { Btu/yr }\end{array}$ \\
\hline $\begin{array}{l}\text { High-purity polycrystalline silicon } \\
\text { production }\end{array}$ & & $4.5 \times 10^{6}$ & \\
\hline Direct & $1.50 \times 10^{6}$ & & $6.70 \times 10^{12}$ \\
\hline Indirect & $7.50 \times 10^{4}$ & & $3.38 \times 10^{11}$ \\
\hline $\begin{array}{l}\text { Equipment, overhead } \\
\text { Total }\end{array}$ & $2.63 \times 10^{5}$ & & $\begin{array}{l}1.18 \times 10^{12} \\
8.22 \times 10^{12}\end{array}$ \\
\hline $\begin{array}{l}\text { High-purity monocrystalline silicon } \\
\text { production and slicing }\end{array}$ & & $2.9 \times 10^{6}$ & \\
\hline Direct & $1.43 \times 10^{5}$ & & $4.15 \times 10^{11}$ \\
\hline Indirect & $3.47 \times 10^{5}$ & & $1.01 \times 10^{12}$ \\
\hline $\begin{array}{l}\text { Equi pment, overhead } \\
\text { Total }\end{array}$ & $5.12 \times 10^{4}$ & & $\begin{array}{l}1.48 \times 10^{11} \\
1.57 \times 10^{12}\end{array}$ \\
\hline
\end{tabular}

Sources: Lindmeyer et al. (1977), Larrabee (1985), Labuda and Clemens (1982), Watts et al. (1980).

TABLE 3.6. Energy for Silicon Wafers Versus Energy for Electronics

\begin{tabular}{lll}
\multicolumn{1}{c}{ Classification } & Total energy, Btu/year \\
Silicon wafer production & $9.79 \times 10^{12}$ \\
Semiconductors, SIC 3674 & $20.9 \times 10^{12}$ \\
Electronics, SIC 367 & $52.5 \times 10^{12}$
\end{tabular}

Information about energy consumption for other processing steps was not available, either in the literature or from interviews with process engineers.

\subsection{TRIBOLOGICAL LOSSES IN THE ELECTRONICS INDUSTRY}

Only a few of the process steps in the electronics industry suffer from loss of energy or materials due to tribological effects. Most of the techniques which allow the production of tiny circuits with very low levels of undesirable impurities do not permit friction and wear to occur. For example, photolithography, etching, doping, and chemical deposition have no tribological 
components. The use of conveyor belts is minimized because air tracks and increasing numbers of robots (see Section 2.0) are used during wafer production.

The primary operations that do have tribological components are: 1) slicing silicon ingots into wafers and subsequent polishing and lapping and dicing the wafers into chips; 2) use of air blowers and fans for the clean rooms required for wafer production (and, increasingly, for PC board production); 3) use of vacuum pumps for chemical vapor deposition, plasma deposition and etching, sputtering, ion plating, and electron beam mask fabrication; 4) drilling and deburring holes for PC board production and assembly of boards into computers and other equipment; and 5) use of conveyor belts for PC boards and related equipment.

In addition to manufacturing processes that have significant tribological components, there are also some tribological problems which reduce the reliability of the electronic components while in operation. Two major operational tribological concerns are the contact wear between contact points in the circuits and magnetic tape and recording head wear in computers. The effects of contact wear are discussed under the materials and losses section, since contact wear is responsible for reliability and materials losses rather than direct energy losses. The effects of magnetic tape and recording head wear, while they can significantly affect system lifetime and reliability (Bhushan et al. 1986), are outside of the scope of this study since they do not directly affect electronics.

Table 3.7 1ists the type of tribological wear occurring in each identified operation.

\subsubsection{Tribological Energy Losses}

Tribological energy losses in the electronics industry are estimated to be quite small. To begin with, the total energy consumption of the whole industry is only about $0.07 \%$ of the energy consumption of the United States (Young et a1. 1985, Bureau of Census 1982). Many processing steps do not experience significant friction and wear, and of those that do, the direct energy losses from friction and wear are a small proportion of total energy consumption. 
TABLE 3.7. Tribological Loss Mechanisms in the Electronics Industry

\begin{tabular}{|c|c|c|c|c|}
\hline Operation & Friction & Abrasion & Adhesion & Tribochemical \\
\hline $\begin{array}{l}\text { Slicing, dicing of } \\
\text { silicon } \\
\text { Lapping, polishing }\end{array}$ & $\begin{array}{l}x \\
x\end{array}$ & $\begin{array}{l}x \\
x\end{array}$ & & \\
\hline Vacuum pumps & $x$ & $x$ & & $x$ \\
\hline Blowers and fans & $x$ & & & \\
\hline Drilling & $x$ & $x$ & & \\
\hline Deburring & $x$ & $x$ & & \\
\hline Conveyors & $x$ & $x$ & & \\
\hline Contact wear & $x$ & & $x$ & $x$ \\
\hline
\end{tabular}

Sources: Imhoff et al. (1985), Czichos (1978).

Operations included in this discussion of direct tribological energy losses are wafer slicing, lapping, and polishing; dicing wafers into chips; the use of vacuum pumps for process steps; the use of blowers and fans in clean rooms; drilling and deburring holes in the $P C$ boards; and the use of conveyor belts for PCs.

Production of silicon wafers is one of the larger energy consuming steps in the electronics industry; it requires about $19 \%$ of the total electronics energy consumption (energy required for production of metallurgical grade silicon has not been included, since these processes are not usually considered to be a part of the electronics industry). However, direct tribological energy losses from the machines used for slicing, lapping, and polishing the wafers represent only about $0.2 \%$ of silicon wafer production energy (Imhoff et al. 1985). The total amount of direct energy losses in silicon wafer production is therefore estimated to be about $8 \times 10^{8} \mathrm{Btu} / \mathrm{yr}$. Additional direct energy loss from dicing the wafers into chips is estimated to be negligible.

Vacuum pumps are becoming increasingly important in the manufacture of integrated circuits. About half of the processing steps are currentiy performed under various degrees of vacuum; this proportion is expected to rise to three quarters of all processing steps in the future ( 0 Hanlon 1985). Direct energy losses associated with friction and wear of vacuum pumps are relatively 
smal1. There are approximately 9250 vacuum pumps of all types now in use in the semiconductor industry. (a) The amount of power required to run these pumps varies tremendously according to the pump size and type. For this calculation, an "average" pump was assumed to require $16,000 \mathrm{Btu} / \mathrm{hr}$ with a range of plus or minus 20\% (Leybold-Heraeus 1985, Little 1976), and to operate $5000 \mathrm{hrs} / \mathrm{yr}$. Since the direct tribological losses for a pump have been estimated to be about 5\% (Imhoff et a1. 1985), the total direct tribological energy loss from vacuum pumps used in the semiconductor industry is about 3 to $4 \times 10^{10} \mathrm{Btu} / \mathrm{yr}$.

In the production of integrated circuits, the energy required to run the blowers and fans used for the clean rooms has a tribological loss component of about 1\% (Imhoff et al. 1985). In the production of printed circuit boards, the tribological energy loss component from drilling and deburring is estimated to be about $0.2 \%$. The tribological loss component from conveyor beits is estimated to be about $5 \%$. Wear of gold-plated sliding contacts is responsible for material and reliability losses, rather than direct energy consumption, and is not included here.

Table 3.8 1ists the order-of-magnitude values for tribological energy loss for the equipment described. It must be emphasized that these are bestestimate values only. Energy consumption data for the electronics industry were not available for most processing steps, due both to a lack of industry interest and a concern for proprietary information. In addition, it is difficult to accurately average the information available for specific types of equipment. The total direct energy losses due to tribology are estimated to be within an order of magnitude of $5 \times 10^{10} \mathrm{Btu} / \mathrm{yr}$.

\subsubsection{Tribological Materials Losses}

Materials loss is more of a concern for the electronics industry than energy loss, because the materials are often very expensive. Major sources of tribological materials loss include the blades used to slice the silicon

(a) Telephone conversation on November 12, 1985, with Mr. Robert Postle, manager of semiconductor market segment, Leybold-Heraeus. 
IABLE 3.8. Direct Tribological Energy Loss in Electronics Industry

Equipment

Slicing, lapping, polishing Wafer dicing into chips

Vacuum pumps

Blowers and fans

Drilling

Deburring

Conveyors

Total

\begin{tabular}{lll}
\multicolumn{2}{c}{ Direct } & Tribological Loss \\
\cline { 1 - 1 } 0.2 & $\frac{8 \times 10^{8}}{\text { Btu/yr }}$ & Range \\
0.2 & $8 \times$ & \\
D.2 & negligible & \\
5 & $4 \times 10^{10}$ & $(3-4)$ \\
1 & $5 \times 10^{9}$ & \\
2 & negligible & \\
0.2 & negligible & \\
5 & $7 \times 10^{9}$ & $(5-10)$ \\
& $5 \times 10^{10}$ & $(4-6)$
\end{tabular}

Sources: Imhoff et al. (1984), Lindmeyer et al. (1977), Bureau of Census (1983), Larrabee (1985), Leybold-Heraeus (1985).

crystals and dice the wafers into chips, the vacuum pumps used to reduce pressure in environments that are often filled with corrosive chemicals, and the gold plating used for circuits.

A stainless steel blade with diamond/adhesive matrix and nickel electroplate, used for slicing silicon crystals into wafers, usually has a lifetime $0^{\text {F }}$ 2000 slices per blade (although blade lifetime for in-house wafer consumption can be twice this figure). Blades are replaced because of metal fatigue due to improper alignment, because of excessive loading of the diamond/adhesive matrix, and because of friction and wear during sawing. (a) An estimate of the percentage of blade replacement due to tribological factors was not attempted.

Approximately 32DD metric tons of silicon ingot were produced in 1982 (Runyan 1982), with an average diameter of $150 \mathrm{~mm}$ (Lane 1985). Since each wafer was approximately $0.500 \mathrm{~mm}$ thick and had a kerf loss of $0.36 \mathrm{~mm}$ (Lane 1985), the total number of ingot slices made in 1982 would have been about $g \times$ $10^{7}$. The number of blades consumed would therefore have been $4.5 \times 10^{4}$. Each

(a) Telephone conversation with N. Jacksen of Optoelectronics, in January 1986. 
blade weighs about a pound, most of which is cold-rolled steel. (a) Since the energy required to produce a ton of steel is approximately $30 \times 10^{6}$ Btu, then the total amount of energy required to manufacture the steel blade cores was about $7 \times 10^{8} \mathrm{Btu} / \mathrm{yr}$. This is a rough approximation of the the indirect energy consumed by the replacement of slicing blades every 2000 slices, with no estimate of the percentage replacement due to tribology.

Friction and wear can be a serious problem for the several types of vacuum pumps with moving parts which are used in semiconductor manufacture. Most of the wear problems occur with rotary vane pumps, since they are often used as "rough pumps", i.e., they stand between the system to be evacuated and the more delicate, ultra-high vacuum pumps such as turbomolecular or cryopumps. Manufacturing processes that cause the most pump wear are chemical vapor deposition and plasma etching, especially of silicon or aluminum. Extremely corrosive chemicals such as chlorine and fluorine compounds are used during these processes. Besides the chemical corrosion this creates, there is also significant damage to pumps caused by the particulates formed from the etchants. Particulates plug up the lubrication oil channels, causing the pumps to seize. They also score the outside of the rotating vanes, which causes the seals to fail and lubricant to leak out. These problems can be so severe that a rotary vane pump used for aluminum etching will typically only last between two weeks and six months before it seizes up and has to be replaced. (b)

To calculate the approximate amount of indirect energy required for the replacement of worn vacuum pumps, the following assumptions were made: 1) 0ut of the 9250 vacuum units now being used in the semiconductor industry about 5000 of them would operate for about three months before failing, (b) about 1000 of them would operate for six months before failure, and about 3250 of them would operate for about a year before failure; 2) each pump would be cleaned and repaired after the first two failures, and replaced with a new pump after the third fajlure, and energy would be required to manufacture the replacement pumps; 3) although pump failures occur due to chemical corrosion as well as to

(a) Telephone conversation with Silicon Technology Corporation representative, August 1985.

(b) Telephone conversation with Robert Postle, Leybold-Heraeus, November 1985. 
particulate wear; however, no attempt was made to separate these failure mechanisms, since chemical corrosion is the main cause of particulate formation; 4) using the listed weights of vacuum pumps (Leybold-Heraeus 1985), the total weight of all the replacement vacuum pumps was estimated to be approximately $\left.6 \times 10^{6} \mathrm{lb} / \mathrm{yr} ; 5\right)$ embodied energy in the steel used for vacuum pumps is $30 \times 10^{6} \mathrm{Btu} / \mathrm{ton}$ (Office of Technology Assessment 1983). The result of these calculations is that approximately $9 \times 10^{10} \mathrm{Btu} / \mathrm{yr}$ are required for the indirect energy used in manufacturing new vacuum pumps to replace those destroyed by particulate wear.

Gold coatings are used for sliding electrical contacts because they have good lubricating properties, high conductance, a high melting point, and good corrosion resistance (Miyakawa 1980). However, gold is a soft metal, and does not wear very we11. Fretting and coating disruption can occur from differential thermal expansions of contact members due to fluctuating ambient temperature, or from external vibrations. Higher contact resistance results from disrupted coatings, and the computer's reliability suffers (Antler 1982). Harder and cheaper alloys have been developed, but so far none of them can match gold's chemical resistance to corrosion and oxidation, lubricating properties, and conductance (Abbot et a1. 1981).

The consumption of gold in the U.S. electronics industry was approximately 111 long tons per year in 1984 (Mining Engineering 1985), which is nearly as much as the total world electronics industry consumption in 1982 (Antler 1982). However, the quantity of gold consumed as a result of tribological coating wear is hard to estimate; circuit boards damaged by displaced coatings are often entirely replaced by the user rather than repaired. The loss of gold due to tribology in sliding contacts was estimated to be about $1 \%$ of the total use of gold in electronics, or 1.1 long tons per year $\left(3.6 \times 10^{4}\right.$ troy ounces per year). The amount of energy needed to manufacture 1.1 long tons of gold is about $3 \times 10^{8}$ Btu per year, which is insignificant compared with the amounts of energy required for replacing slicing blades and vacuum pumps (Lucas 1986).

Table 3.9 gives an order-of-magnitude estimate of the indirect energy loss to the electronics industry due to replacement of tribologically worn slicing blades, vacuum pumps, and sliding contacts. 
TABLE 3.9. Indirect Tribological Energy Losses in the Electronics Industry

\begin{tabular}{|c|c|c|}
\hline Material & Quantity of loss & $\begin{array}{c}\text { Energy Loss } \\
\text { Btu/yr } \\
\end{array}$ \\
\hline Slicing blades & $4.5 \times 10^{4}$ blades $/ y r$ & $7 \times 10^{8}$ \\
\hline Vacuum pumps & 8400 pumps/yr & $9 \times 10^{10}$ \\
\hline $\begin{array}{l}\text { Gold coatings } \\
\text { Total }\end{array}$ & 1.1 long ton $/ y r$ & $\begin{array}{l}3 \times 10^{8} \\
9 \times 10^{10}\end{array}$ \\
\hline
\end{tabular}

Sources: Antler (1982), Mining Engineering (1985), Jacksen (1985), Office of Technology Assessment (1983), Leybold-Heraeus (1985), Labuda and Clemens (1982), Lane (1985), Lucas (1986).

\subsubsection{Tribological Monetary Losses}

Replacing materials lost due to tribological effects in the electronics industry requires relatively small amounts of manufacturing energy. However, the monetary costs of materials replacenent are uncomfortably high. Consequentiy, there has been a substantial amount of research conducted on reducing materials costs, including development of new ingot slicing techniques and new filters to improve the 1 ifetime of vacuum pumps, and reducing and/or replacement of gold coatings.

81 ades used for inner diameter slicing of silicon ingots currently cost about $\$ 120$ each, and for most commercial applications they are replaced after 2000 slices. (a) Multiblade wafering saws, which can use 300 blades at once with a free abrasive slurry, are used for optical materials and photovoltaic silicon since they are more adaptable and cheaper per slice. However, they are not used for semiconductor-grade silicon because parallelism and uniformity of slice thickness is not as good as with an inner diameter saw (Jacksen 1985). Since the number of inner diameter blades consumed per year was estimated to be $4.5 \times 10^{4}$ blades/yr (Section 3.5.2), the total cost just for new blades is over 5 million dollars per year.

(a) Telephone conversation with Silicon Technology Corporation representative, August 1985. 
The cost of a new vacuum pump is determined by the size and the type of pump. For example, a small rotary vane pump designed for use in a corrosive atmosphere costs about $\$ 1200$, with an additional $\$ 2000$ for an $0 i 1$ filtering system; a large corrosive-application turbomolecular pump costs about $\$ 18,000$, with about $\$ 3000$ of additional accessories (Leybold-Heraeus 1985). Replacement. pump costs are high because the lifetime of the pump is very short due to the harsh use environment. New filters are being developed so that corrosive vapors and particulates will be more effectively prevented from contaminating the pump oil. (a)

To calculate the amount of money spent to replace nonrepairable vacuum pumps, the following assumptions were made: 1) the average cost of rotary vane, roots, and piston pumps and accessories is $\$ 7000 ; 2$ ) the average cost of a turbopump is $\$ 15,000$, including accessories; and 3 ) the average cost of all other vacuum pumps is about $\$ 10,000$. Using the lifetime assumptions made for indirect energy requirements (Section 3.5.2), the total amount of money spent every year for replacement vacuum pumps is about $\$ 67$ million per year. Repair costs were not estimated, but are likely to be even higher.

A tremendous amount of research has been done on developing new materials and alloys, some of which contain gold, to replace the pure gold coatings on contacts (Abbot et al. 1981, Antler 1982, Pope and Rohde 1982). The electronics industry spent a total of about one billion dollars for gold in 1985 (Mining Engineering 1985), which gives researchers a powerful motivation to find a cheaper substitute. However, gold has yet to be displaced as the most acceptable contact coating. Since it was estimated that approximately $1 \%$ of all gold is replaced due to tribological wear (Section 3.5.2), the monetary loss would be about $\$ 10$ million per year.

The additionat energy required because of direct and indirect tribological losses has an economic cost. The lost energy is mostly in the form of electricity, since electricity is required for the operation of equipment with associated tribological losses such as vacuum pumps, slicing machines, and clean room fans and blowers. Assuming an electricity cost of $\$ 0.05 / \mathrm{kWh}$

(a) Telephone conversation with Robert Postle, Leybold-Heraeus, November 1985. 
(Miedema and Stern 1985), then the total direct energy losses of $5 \times 10^{10}$ Btu per year would cost $\$ 7.3 \times 10^{5}$. The indirect losses of $9 \times 10^{10}$ Btu/year would cost $\$ 1.3 \times 10^{6}$. Total energy costs due to tribological losses would be $\$ 2.05$ $\times 10^{6}$ per year.

The total monetary losses due to replacement of tribologically worn materials and the cost of tribological energy losses are summarized in Table 3.10. Within an order of magnitude, at least $\$ 84$ million per year is lost in replacing worn materials in the electronics industry. The largest fraction results from the replacement of worn vacuum pumps.

\subsection{CONCLUSIONS}

The electronics industry is a relatively small energy consumer, although trends may change with the expansion of the electronics market. The electronics industry currently consumes about $0.07 \%$ of the total energy used in this country, and tribological energy losses represent only $0.3 \%$ of this percentage. This is primarily because most of the processing steps either do not have tribological components, such as with resistance heating, light exposure, and

\section{TABLE 3.10. Tribological Monetary Losses}

\begin{tabular}{|c|c|c|c|}
\hline Item & Quantity/yr & $\$$ /unit & Total $\$ / y r$ \\
\hline Slicing blades & $4.5 \times 10^{4}$ & $\$ 120 /$ blade & $\$ 5.4 \times 10^{6}$ \\
\hline \multicolumn{4}{|l|}{ Vacuum pumps } \\
\hline $\begin{array}{l}\text { Vane, roots, } \\
\text { piston }\end{array}$ & 6700 & $\$ 7000 /$ pump & $\$ 47 \times 10^{6}$ \\
\hline Turbo & 670 & $\$ 15,000 /$ pump & $\$ 10 \times 10^{6}$ \\
\hline Other & 1000 & $\$ 10,000 /$ pump & $\$ 10 \times 10^{6}$ \\
\hline Gold & $3.6 \times 10^{4}$ troy $0 z$ & $\$ 317 /$ troy oz & $\$ 10 \times 10^{6}$ \\
\hline Energy losses & $14 \times 10^{10} \mathrm{Btu} / \mathrm{yr}$ & $\$ 0.05 / \mathrm{kWh}$ & $\$ 2 \times 10^{6}$ \\
\hline Total & & & $\$ 84 \times 10^{6}$ \\
\hline
\end{tabular}

Sources: Mining Engineering (1985), Lucas (1986), Jacksen (1985), Leybold-Heraeus (1985), Mídema and Stein (1985). 
chemical solution etching; or else friction and wear is peripheral to the processing step, such as the wear of vacuum pumps used for vapor deposition and clean room fans.

The largest source of direct tribological energy loss are the vacuum pumps used for many different processing steps. Other major sources of direct tribological energy loss include the slicing, lapping, and polishing of silicon wafers, the blowers and fans used in clean rooms, and the conveyor belts used for printed circuit manufacture. Direct tribological energy losses from dicing the wafers into chips and from drilling and deburring holes in PC boards are insignificant. The major source of both indirect tribological energy and monetary losses is replacing worn vacuum pumps; their lifetime is short, they contain a lot of steel, and they are very expensive. Compared to the indirect energy consumption for pump replacement, the indirect energy requirements for replacing worn slicing blades and for replacing worn gold coatings is insignificant. However, the monetary losses from wear of the slicing blades and gold coatings are substantial, because these items have high unit costs. The monetary losses resulting from increased energy requirements due to tribological losses are aiso significant.

The total direct energy loss in the electronics industry due to tribology is estimated to be $5 \times 10^{10} \mathrm{Btu} /$ year. Total indirect energy loss due to tribology is estimated to be $9 \times 10^{10}$ Btu/year, or nearly twice as much as the direct energy losses. Total monetary losses from tribological causes are estimated to be $\$ 84$ million per year. These numbers are order-of-magnitude estimates only. Detailed information about current energy consumption was available only for those electronics operations that are also used in photovoltaic cell production. The quantities of materials to be replaced due to tribological wear, and their embodied energy, could only be crudely estimated from the sketchy information available. 
REFERENCES AND BIBLIOGRAPHY

ASTM Standardization NEWS. "New Robot Orders Rise." October 1985.

Abbot, W. F., et al. 1981. "Impact of Precious Metal Cost on Connection Systems." In Proceedings of the 27th Annual. Meeting of the Holm Conference on Electrical Contacts. ITlinois Institute of Technology, Chicago, IlTinois.

Antler, M. 1982. "Application of Palladium in Electronic Connectors." Platinum Metals Review. 26(3):106-117.

Albus, J. 1984. Robotics, Robots and Artificial Intelligence. M. Brady, et al., eds. NATO ASI Series, Springer-Verlay, New York.

Baranson, J. 1983. Robots in Manufacturing Key to International Competitiveness. Lomond Publications, lnc., Mt. Airy, Maryland.

Bhushan, B., G. W. Nelson, and M. E. Wacks. 1986. "Head-Wear Measurements by Autoradiography of the Worn Magnetic Tapes." Journal of Tribology. $108(1): 22-29$.

Bureau of the Census. 1983. 1982 Census of Manufacturers: Fuels and Electric Energy Consumed, Part 1. U.S. Departiment of Commerce, Washington, D.C.

Burnett, J. 1985. "Clean Rooms for VLSl Manufacturing: Class One Practice." Solid State Technology. September 1985, pp. 121-123.

Chang, C. C. 1982. "Semiconductors (Fabrication)." In Kirk-Othmer Encyclopedia of Chemical Technology, pp 634-654, John Wiley and Sons, New York.

Cohen, P. 1985. "Whatever Happened to the Robot Boom?" Presented at Robots 9 Conference, June 2-6, 1985, Detroit, Michigan.

Conigliaro, L. 1985. "Robotics and Vision: The Hazards of Covering these Industries." Presented at Robots 9 Conference, June 2-6, 1985, Detroit, Michigan.

Cowick, R. 1985. "Maintenance of Robots." Presented at Robots 9 Conference, June 2-6, 1985, Detroit, Michigan.

Czichos, H. 1978. Tribology: A Systems Approach to the Science and Technology of Friction, Lubrication, and Wear. Elsevier Scientific Publishing Company, New York.

Daud, T., and Kachare, A. H. 1982. Advanced Czochralski Silicon Growth Technology for Photovoltaic Modules. DOE/JPL-1012-70, Jet Propulsion Laboratory, Pasadena, California.

Fonash, S. J. 1985. "Advances in Dry Etching Processes-A Review." Soljd State Technology. January 1985, pp. 150-158. 
Ford, D. 1985. "Using Clean Room Technology Selectively." Circuits Manufacturing. April 1985, pp 50-51.

Fredkin, E. 1984. "Robotics." Research Development, June 1984, pp. 243-249.

Gariepy, G. B. 1985. "Diamond Blade Technology in Die Separation." Solid State Technology. July 1985, pp. 95-99.

George, R. 1983. "Evaluating Bearings for Robotics," Machine Design. April 7, 1983.

Guterl, Fred. 1984. "In Pursuit of the One-Month Chip." IEEE Spectrum. September 1984, pp. 28-49.

Harman, G. G. and F. F. Gettinger. 1985. "Bonding and Packaging." Solid State Technology. July 1985, P. 65.

Hoenig, S. A. 1985. "The Clean Room as a System for Contamination Control." Solid State Technology. September 1985, pp. 129-135.

Imhoff, C. H., et al. 1985. A Review of Tribological Sinks in Six Major Industries. PNL-5535, Pacific Northwest Laboratory, Richland, washington.

Industrial Heating. 1985. "Federal Triangle." November 1985.

International Trade Administration (ITA). 1984. A Competitive Assessment of the U.S. Manufacturing Automation Equipment Industries. U.S. Department of Commerce, Washington, D.C.

International Trade Administration (ITA). 1986. Industrial Outlook 1986. U.S. Department of Commerce, Washington, D.C.

Jacksen, N. 1985. "Materials and Technology of Wafering." Solid State Technology. Juty 1985, pp. 107-114.

Japan Economic Institute. 1984. "U.S.-Japan Competition in Robots: An Update." JEI Report, March 2, 1984. Japan Economic Institute, Washington, D.C.

Kayex Corporation. 1981. "Advanced Czochralski Ingot Growth." In Progress Report 19: Proceedings of the 19th Project Integration Meeting. DODE/JPL1012-67, Jet Propulsion Laboratory, Pasadena, California.

Keys, R. W. 1985. Electronic Design. January 10, 1985, pp 278-279.

Koren, Yoram. 1985. Robotics for Engineers. McGraw-Hill Book Co., New York.

Kurnik, R. T. 1985. "Chemical Vapor Deposition in Microelectronics." Chemical Engineering Progress. May 1985, pp. 30-35. 
Labuda, E. F., and J. T. Clemens. 1982. "Integrated Circuits." In KirkOthmer Encyclopedia of Chemical Technology, pp 621-648, John Wiley and Sons, New York.

Lane, R. L. 1985. "ID Slicing Technology for Large Diameters." Solid State Technology. July 1985, pp. 119-123.

Larrabee, G. B. 1985. "Microelectronics: A Challenge to Chemical Engineers." Chemical Engineering, June 10, 1985, pp 51-59.

Lau, J. H., and D. W. Rice. 1985. "Solder Joint Fatigue in Surface Mount Technology: State of the Art." Solid State Technology. October 1985, pp. 91-104.

Leybold-Heraeus, Inc. 1985. Product and Vacuum Technology Reference Book, 1985-1986. Company-produced catalogue. Laybold-Heraeus, Inc., San Jose, CaTifornita.

Lindmeyer, J., et al. 1977. Energy Requirement for the Production of Silicon Solar Arrays. D0E/JPL 954606-4, Solarex Corporation, Rockville, Maryland.

A. D. Little Company. 1976. Energy Efficiency and Electric Motors. FEA-1076131, NTIS PB-259129. National Technical Information Service, Springfield, Virginia.

Lucas, J. M. 1986. "Gold." Mining Engineering. May 1986, pp. 332-333.

Miedema, A. K., and K. M. Stern. 1985. Commercial and Industrial Response to Time-of-Use Rates, EPRI-EA-4206, Electric Power Research Institute, Palo ATto, California.

Mining Engineering. 1985. "Gold Use in Electronics Industry Reaches Record High in 1984." October 1985, p. 1192.

Miyakawa, Y. 1980. "Friction and Wear Performance of Gold and Gold Alloy Films." Gold Bulletin. 13(1):21-30.

Mokashi, A. R. 1982. Price Estimates for the Production of Wafers from Silicon Ingots. D0E/JPL-1012-74, Jet Propulsion Laboratory, Pasadena, Catifornia.

Nof, S. Y., Ed. 1985. Handbook of Industrial Robotics. John Wiley \& Sons, New York.

O'Hanlon, J. F. 1985. "Vacuum Systems for Microelectronics." Solid State Technology. November 1985, pp. 103-107.

Office of Technology Assessment (OTA). 1983. Industrial Energy Use. OTA-E-198, Office of Technology Assessment, Washington, D.C. 
Pogge, H. B. 1985. "Material Aspects of Semiconductors." Chemtech. August 1985, pp. 497-503.

Pope, L. E., and R. W. Rohde. 1982. The Effect of Environment and Materials Properties on the Friction and Wear Behavior of Precious-Metal ElectricalContact Alloy CoupTes. SAND-82-2770C, Sandia National Laboratories, Albequerque, New Mexico.

Robotic Industries Association (RIA). 1985. Worldwide Robotics Survey and Directory. Robotic Industries Association, Dearborn, Michigan.

Runyan, W. 1982. "Silicon and Alloys (Pure Silicon)", in Encyclopedia of Chemical Technology, Volume 20, pp. 835-845. Published by John Wiley and Sons, New York.

Saint Pierre, A. 1985. "Robotics in the Finishing Room." Tappi Journal. $68(10)$.

Smith, D. and R. Wilson. 1983. Industrial Robots--A Delphi Forecast of Markets and Technology. Society of Manufacturing Engineers, Ann Arbor, Michigan.

Stover, H. L. 1985. "Dptical Lithography." Solid State Technology. January 1985, p. 117.

Tappi Journal. 1983. "Robots, CADLCAM to Lead 1980s Autonation Surge." $66(10)$.

Watts, R. L., et al. 1980. The Evaluation of Critical Materials for Five Advanced Design Photovoltaic Cells with an Assessment of Indium and GalTium, PNL-3319, Pacific Northwest Laboratory, Richland, Washington.

Webster's Third New International Dictionary. 1976. G\&C Merriam and Co., Springfield, Massachusetts.

Wilson, G. C. 1969. "Multilayer Printed Circuit Wiring." In The Production of Printed Circuits and Electronic Assemblies. C. R. Draper, ed. Robert Draper, Ltd., Teddington, England.

Wilson, A. D. 1986. "X-Ray Lithography: Can It Be Justified?" Solid State Technology. May 1986, pp. 249-255.

Young, J. K., E. A. Griffin and J. A. Russell. 1984. Opportunities for Energy Conservation Through Biotechnology. PNL-5295, Pacific Northwest Laboratory. Richland, washington.

Zeldman, Maurice. 1984. What Every Engineer Should Know About Robotics. Marcel Dekker, Inc., New York. 


\section{DISTR IBUTION}

No. of

Copies

DFFSITE

36 T. Levinson

U.S. Department of Energy

Forrestal Building CE-142

Washington, DC 20585

J. J. Eberhardt

U.S. Department of Energy

Forrestal Building

Mail Stop 6B025

Washington, DC 20585

S. Goguen

U.S. Department of Energy CE 131

Mailstop 5E 043

Forrestal Building

1000 Independence Ave., SW

Washington, DC 20585

30 DOE Technical Information

Center

A. Anderson

Multi-Arc Vacuum Systems Inc.

261 East 5th Avenue

St. Pau 1, MN 55101

C. Albertson

Borg-Warner Corporation

1200 South Wolf Road

Des Plaines, IL 60018

S. Barber

Battelle-Columbus Laboratories

505 King Avenue

Columbia, OH 43201-2693

P. N. Blumberg

Integral Technologies, Inc.

415 East Plaza Drive

Westmont, IL 60559
No. of

Copies

L. J. Brombolich

Compu-Tec Engr. Inc.

300 Chesterfield Center, 205

Chesterfield, M0 63017

W. Bryzik

U.S. ArTIY TACOM

AMSTA-RGR

Warren, MI 48090

D. H. Buckley

NASA/Lewis Research Center

23-2

Cleveland, $\mathrm{OH} \quad 44135$

R. F. Bunshah

Department of Materials Science

University of California at

Los Angeles

6532 Boelter Hall

Los Angeles, CA 90024

J. A. Carpenter, Jr. Oak Ridge National Laboratory

P.0. Box $X$, Building 4508

Oak Ridge, TN 37831

F. J. Carignan

Advanced Mechanical

Technology Inc.

141 California Street

Newton, MA 02158

H. S. Cheng

Dept. of Mechanical Engineering

Center for Engineering

Tribology

Northwestern University

Evanston, IL 60201

G. W. Clark

Oak Ridge National Laboratory

P.0. Box $X$, Building 4508

Oak Ridge, TN 37831 
No. of

Copies
No. of

Copies

\author{
M. J. Cronin \\ Mechanical Technology, Inc. \\ 968 Albany-Shaker Road \\ Latham, NY 12110 \\ J. L. Duda \\ Pennsylvania State University \\ 133 Fenske Laboratory \\ University Park, PA 16802 \\ J. F. Dill \\ Mechanical Technology Inc. \\ 968 Albany-Shaker Road \\ Latham, NY 12110

\section{R. Erickson} \\ Battelle-Columbus Laboratories \\ 505 King Avenue \\ Columbus, $\mathrm{OH}$ 43201-2963
}

L. L. Fehrenbacher

2002 Huntwood Drive

Huntington Woods

Gambrills, MD 21054

D. G. Flom

General Electric Company

Corporate R\&D, 4B4, K-1

P. 0 . Box 8

Schenectady, NY 12301

T. Fischer

Exxon Research

Clinton Township Route 22 East

Annandale, NJ 08801

T. Gruber

Battelle-Columbus Laboratories

$505 \mathrm{King}$ Avenue

Columbus, $\mathrm{OH}$ 43201-2693

J. Horwath

Borg-Warner Corporation

Ingersoll Research Center

1200 S. Wolf Road

Des Plaines, IL 60018
S. M. $\mathrm{H} 5 \mathrm{U}$

Room A257, Building 223

Inorganic Materials Division

National Bureau of Standards

Gäithersburg, M0 20899

N. S. Hakim (R03B)

Detroit Diesel Altison Division 36880 Ecorse Road

Romulus, MI 48174

C. R. Houska

Dept. of Materials Engineering

Virginia Polytechnic Institute

Blacksburg, VA 24061

Dr. Niels Jacksen

Optoelectronics

1309 Dynamic Street

Petaluma, CA 94952

12 Lee Northcutt

Argonne National Laboratory

9700 South Cass

Argonne, IL 60439

R. Krutenat, 102/0217

Exxon Research and Engineering $\mathrm{Co}$.

Florham Park, NJ 07932

S. Khanna

Solid State Science Research Group

Jet Propulsion Laboratory

4800 Oak Grove Drive

MS 122-123

Pasadena, CA 91109

F. F. Ling

Mechanical Engineering

Jonsson Engineering Center

Rensselaer Polytechnic Inst itute

Troy, NY 12181 
No. of

Copies

H. Khac Le

DHR Inc.

6849 01d Dominion Drive

McLean, VA 22101

H. E. McCormick

Director of Engineering

Ramsey Piston Ring Division

TRW Automotive Products, Inc. 1233 Manchester Road

Manchester, MO 63011

C. Mecklenburg

AFWAL/MLBT

Wright Patterson AFB

Dayton, $\mathrm{OH}$ 45433-6533

J. MeCool

SKF Industries

1100 First Avenue

King of Prussia, PA 19406

T. Merriman

Battelle-Columbus Laboratories

505 King Avenue

Columbus, $\mathrm{OH}$ 43201-2693

J. R. Mullaly

Pratt \& Whitney Aircraft

P.0. Box 2691

MS 707-28

West Palm Beach, FL 33402

M. B. Peterson

Wear Sciences, Inc.

925 Mallard Circle

Arnold, MD 21012

0. Pinkus

Mechanical Technology Inc.

968 Albany-Shaker Road

Latham, NY 12110

Dr. Robert Postle

Leybold-Heraeus Vacuum Products

5700 Mellon Road

Export, PA 15632
No. of

Copies

T. F. J. Quinn

Tribology and Rheology Laboratory

School of Mechanical

Engineering

Georgia Institue of Technology

Atlanta, GA 30332

R. C. Rosenberg

General Motors Research Laboratory

Fluid Mechanics Department Warren, MI 48090

A. W. Ruff

National Bureau of Standards

Metallurgy Division

Room B266-Materials Building

Gaithersburg, MD 20899

W. D. Sproul

Borg-Warner Corporation

1200 South wolf Road

Des Plaines, IL 60018

L. B. Sibley

Tribology Consultants, Inc.

504 Foxwood Lane

Paoli, PA 19301

A. C. Schaffhauser

Oak Ridge National Laboratory

P.0. Box $X$

Oak Ridge, TN 37831

I. L. Singer

Naval Research Laboratory

Code 6170

Washington, DC 20375

T. C. Spalvins

NASA/Lewis Research Center

MS 23-2

Cleveland, $\mathrm{OH} \quad 44135$ 
No. of

Copies

D. F. Wilcock, President

Tribolock, Inc. 1949 Hexham Road

Schenectady, NY 12309

W. 0 . Winer

Tribology and Rheology Laboratory

School of Mechanical Engineering

Georgia Institute of Technology

At lanta, GA 30332

C. S. Yust

Metals and Ceramics Division

Oak Ridge National Laboratory

P.0. Box $X$

Oak Ridge, TN 37831

M. Zlotnick

141 East 88th Street

New York, NY 10028
No. of

Copies

C. A. Zanis

Department of the Navy

Naval Sea Systems Command

Research and Development office

Washington, DC 20362

DNSITE

DOE Richland Operations office

J. J. Sutey

34 Pacific Northwest Laboratory

W. B. Ashton (6)

D. L. Brenchley (6)

G. J. Hane (6)

R. A. Hutchinson

C. H. Imhoff

J. A. Russell (6)

M. T. Thomas

Publishing Coordination MH (2)

Technical Information (5) 